\title{
Notas botánicas sobre aislamiento y contacto. Plantas y vestigios hi-merimã (río Purús/ Amazonía brasileña)
}

Dedicado a la memoria de Dueña Inês

y Berinawa Jamamadi

\section{Daniel Cangussu}

iD https://orcid.org/0000-0001-5744-6319

Fundación Nacional del Indígena (FUNAI), Brasil

cangussu.isolados@gmail.com

\section{Karen Shiratori}

(iD) https://orcid.org/0000-0002-0297-0962

Centro de Estudios Amerindios (CEstA), Universidad de São Paulo, Brasil

Unidad Mixta de Investigación «Patrimoines locaux, Environnement \&

Globalisation» (PALOC-IRD)

karen.shiratori@gmail.com

\section{Laura Furquim}

(iD) https://orcid.org/0000-0001-8425-3125

Laboratorio de Arqueología Tropics (MAE / USP), Brasil

laura.uanda@gmail.com

RESUMEN

Con el fin de restaurar, aunque parcialmente, la memoria de las intensas relaciones que existían entre los distintos pueblos arawá de la región del medio curso del río Purus, este artículo aborda, a través del entrelazamiento de la vida humana y la vegetal, la socialidad que acabó rompiéndose, las historias que algún día se compartieron, pero también los vínculos que aún reverdecen en los bosques. La ciencia matera, atenta a las plantas y a los vestigios antrópicos presentes en los bosques, muestra caminos insospechados 
para analizar las complejas relaciones entre los hi-merimã, actualmente aislados, y sus vecinos, especialmente los jamamadi. En este texto, proponemos un análisis del relato de un encuentro a través de notas que demuestran la centralidad y fecundidad de las plantas para la comprensión de la sociabilidad y la dinámica territorial mi-merimã. Las notas se basan en datos bibliográficos oriundos de estudios antropológicos, arqueológicos y botánicos, así como en información obtenida de los pueblos indígenas y de los habitantes ribereños de la zona.

Palabras clave: ecología histórica, etnología arawá, ciencia matera, pueblos indígenas aislados, Amazonía brasileña

\title{
Notas botânicas sobre isolamento e contato. Plantas e vestígios de Hi-merimã (rio Purus / Amazônia brasileira)
}

\author{
RESUMO
}

Em vista de restituir, ainda que parcialmente, a memória das intensas relações que vigoravam entre os diferentes povos arawá na região do médio Purus, este artigo aborda, por meio do entrelaçamento da vida humana e vegetal, a socialidade que acabou rompida, as histórias outrora partilhadas, mas também os vínculos que ainda verdejam nas florestas. A ciência mateira atenta às plantas e aos vestígios antrópicos presentes nas matas mostra caminhos insuspeitos para analisar as complexas relações entre os Hi-Merimã, atualmente em isolamento, e seus vizinhos, em especial, os Jamamadi. Neste texto, propomos uma análise do relato de um encontro através de notas que demonstram a centralidade e fecundidade das plantas para a compreensão da socialidade e dinâmica territorial dos Hi-Merimã. As notas fundamentam-se em dados bibliográficos de trabalhos antropológicos, arqueológicos e botânicos, bem como das informações obtidas junto aos povos indígenas e ribeirinhos do entorno.

Palavras-chave: ecologia histórica, etnologia arawá, ciência mateira, povos indigenas isolados, Amazônia brasileira 


\title{
Botanical notes on isolation and contact. Hi-Merimã plants and vestiges (Purus river/Brazilian Amazon)
}

\author{
ABSTRACT
}

In order to recover, even partially, the memory of the intense relations that existed among the different Arawá people in the middle Purus region, this article explores, through the intertwining of human and plant life, the sociality that was broken, the stories that were once shared, but also the bonds that are still flourishing in the forests. The forester science, attentive to plants and anthropic vestiges present in the forests, shows unsuspected ways to analyze the complex relationships between the Hi-Merimã, who are now in isolation, and their neighbors, especially the Jamamadi. In this text, we propose an analysis of the narrative of an encounter through notes that demonstrate the centrality and fecundity of plants for the understanding of Hi-Merimã sociality and territorial dynamics. The notes are based on bibliographic data from anthropological, archeological and botanical studies, as well as information obtained from the indigenous peoples and river communities in the area.

Keywords: historical ecology, Arawá ethnology, forester science, isolated indigenous peoples, Brazilian Amazon 
INTRODUCCIÓN

Interpele o mato a brotação a seiva que borda obras custosas de artesão [...]

Trilha, Leonardo Fróes

En la Amazonía brasileña viven distintos grupos indígenas actualmente en aislamiento. Según datos de la Fundação Nacional do Indio - FUNAI, son aproximadamente 120 registros, veintiocho de estos confirmados (Instituto Socioambiental, 2019). La categoría oficial de «aislados», término con el cual son denominados en la política indigenista, aún no contempla la pluralidad de las experiencias históricas propias del proceso de aislamiento y, al mismo tiempo, del rechazo perdurable del contacto, ya sea con otros pueblos indígenas, ya sea con los no indígenas.

Muchos de estos pueblos vivieron episodios traumáticos de contacto, invariablemente marcados por epidemias, violencia de todo tipo y esclavitud. Sin embargo, estas historias han sido sepultadas por el peso y por la incomprensión que la noción de aislamiento provoca; «si ningún pueblo es una isla», en las palabras del antropólogo Eduardo Viveiros de Castro (2019) vale la pena recuperar, en virtud de un retrato menos impreciso, la memoria de las relaciones intensas entre estos diferentes pueblos, de los lazos de parentesco que se rompieron y de las historias que alguna vez se compartieron. Las veredas guardan vínculos que aún reverdecen en la selva, como los bosques de tierras firmes del interfluvio entre los ríos Purus y Cuniuá (Amazonía brasileña), en donde se registra el pasaje de algunos pueblos arawá, objeto del presente trabajo ${ }^{1}$.

1 Ese texto se inserta en un proyecto conjunto que originó otros trabajos ya publicados o en proceso de edición. De abordaje interdisciplinario, estos textos fueron escritos conjuntamente por los autores que en los últimos años se han dedicado a la investigación en alianza con los pueblos indígenas de la región del curso medio del río Purús. (Manual Indigenista Mateiro, 2021; Life in tree scenarios: plant controversies between Jammadi gardens and Hi-Merimã palm orchads (Middle Purus River, Amazonas, Brazil), Journal of Anthropological Archaeology, 64, 2021); Arqueologia e política do não-contato: sobre monitoramento e proteção 
Los hi-merimã, pueblo indígena arawá ${ }^{2}$ actualmente aislado, habitantes de la Tierra Indígena homónima ubicada en la región del medio curso del río Purus (estado de Amazonas), mantuvieron intensos contactos con los pueblos indígenas de su entorno hasta, por lo menos, la década de 1960. Relatos de los jamamadi (Shiratori, 2018), pueblo indígena vecino con quienes algunos grupos hi-merimã se volvieron corresidentes luego del episodio de aislamiento, muestran que, en común, compartían la dinámica de dispersión territorial, distintas formas de manejo vegetal, además de calendarios rituales y de visitas en virtud de la ayaka, fiesta de la menarquía. También mantenían intensos lazos de parentesco, así como de agresiones chamánicas ${ }^{3}$. Con el asentamiento permanente de no indígenas en las tierras firmes de la región, sobre todo caucheros, gateros ${ }^{4} \mathrm{y}$ regatones, los episodios de evitación y alejamiento permanentes se interpusieron en la historia común de la constelación de diversos grupos arawá.

Esta escisión reconfiguró la organización y las dinámicas sociocosmológicas en la región: los sobrevivientes de las malocas plagadas por sucesivas epidemias y masacres llevadas a cabo por los patrones del caucho se unieron finalmente a otros grupos arawá que posteriormente fueron reconocidos bajo su etnónimo jamamadi (Shiratori, 2018). De este escenario emergieron realidades distintas: por un lado, el rechazo de los hi-merimã al contacto; por el otro, los cambios políticos, sociales y territoriales que los jamamadi enfrentaron con la invasión

dos territórios de povos indígenas isolados na Amazônia sob a ótica da Ecologia Histórica (en prensa); Árvores Atraentes: a sedução vegetal e os povos indígenas em isolamento na Amazônia brasileira (en prensa).

2 Arawá es una familia lingüística formada por los pueblos jamamadi, jarawara, banawá, deni, paumari, suruwaha y, posiblemente, los hi-merimã, todos ellos habitantes del medio curso del río Purús. De la misma familia arawá, los kulina viven en el alto curso del río Purús, en el río Juruá y sus afluentes.

3 El tema transborda el objetivo de este artículo; para el presente argumento, basta tener en cuenta un episodio contado en innumerables ocasiones por Daniel Jamamadi, hijo de padres hi-merimã que huyó, acompañado de sus hermanos, con un grupo de sobrevivientes de su maloca en el río Sabuhã, afluente del río Piranhas, luego de que una epidemia de sarampión acabara con ese núcleo hi-merimã. Con la muerte de los padres, los cinco sobrevivientes se fueron a vivir con un subgrupo jamamadi, los nakanike. La vida en las regiones de las cabeceras en donde se ubicaban las malocas hi-merimã al momento de la llegada de los patrones del caucho ha sido prácticamente agotada por los sucesivos enfrentamientos con los no indígenas. Aunque el etnónimo jamamadi se ha convertido en una categoría global, esto no significa que los vínculos con otros subgrupos madi hayan sido borrados o que ya no tengan relevancia para la actual socialidad marcada por ese nombre. Sobre las agresiones chamánicas entre los subgrupos jamamadi, ver Shiratori (2018).

4 Término con el que se conocen los cazadores de felinos que negociaban sus pieles, muy valoradas en su tiempo. 
permanente de su mundo. El proceso de aglutinación generado por la acción de patrones del caucho y grupos de misioneros proselitistas, con el consentimiento y el respaldo del Estado, o que contaron de forma oportunista con su inacción, reunió parte de los remanentes de estos grupos en asentamientos más grandes, tales como la aldea São Francisco en la Tierra Indígena Jamamadi/Jarawara/ Kanamati, y la aldea Maloca, en la Tierra Indígena Banawá (Aparício, 2019).

Investigaciones recientes de carácter etnográfico, ecológico e historiográfico llevadas a cabo en la región del interfluvio Juruá-Purus han contribuido, en su conjunto, a establecer una comprensión más detallada de las dinámicas y de la socialidad arawá. En ese contexto, se subraya la prominencia de las plantas en los análisis, que dan como resultado transformaciones tanto metodológicas como teóricas que señalan y abren caminos para nuevas hipótesis y agendas de investigación específicas a estos pueblos, pero que, sin embargo, están en línea con un movimiento interdisciplinario más amplio de reconocimiento de la dignidad existencial de las plantas, de su fecundidad epistemológica y relevancia cosmopolítica (Oliveira, 2015 y 2019; Shiratori, 2018, 2019, 2021; Morim de Lima, 2019, 2021; Carneiro da Cunha, 2020; Aparício, 2020; Neves, 2021; Furquim, 2021; entre otros).

El resurgimiento del interés por las plantas también se manifiesta a través de las actuales propuestas de perfeccionamiento metodológico para la renovación de la política de protección territorial de los pueblos indígenas en aislamiento (Cangussu, 2021). Los troncos, las hojas y sus tejidos vegetales, así como los ciclos ecológicos de las especies de una región, revelan incluso los vestigios humanos más difusos inscritos en los bosques como lazos de la relación de los pueblos indígenas con la diversidad forestal y del conocimiento profundo que tienen de ella. Sumado a esto, se encuentran distintos vestigios materiales de la presencia de pueblos aislados a lo largo de los senderos recorridos durante el monitoreo de tales pueblos: campamentos con sus hogueras, vasijas cerámicas, canastas, antorchas, morteros, instrumentos utilizados para el corte de las cazas y árboles, entre otros artefactos, que conservan informaciones sobre los modos de vida y las relaciones de estos grupos. Estos vestigios constituyen el objeto de trabajo de la arqueología del tiempo presente, orientada a la comprensión de los contextos indígenas en aislamiento (Cangussu, 2021; Cangussu et al., en prensa) ${ }^{5}$.

La arqueología del tiempo presente, planteada en contextos territoriales de pueblos en aislamiento, es una hipótesis que estamos elaborando en un proyecto conjunto y en alianza con arqueólogos actuantes en diferentes contextos de investigación. 
Esa atención al mundo sensible se expresa en la mirada de los materos, en general moradores de la región, a menudo indígenas, que componen los equipos de expedición responsables por las acciones de protección y monitoreo de los territorios habitados por grupos aislados. Esta ciencia, de ahora en adelante denominada como matera (Cangussu, 2021), tiene sus raíces en la selva amazónica, en el conocimiento local de los pueblos que la habitan, ya sean ribereños, extractivistas, caucheros, indígenas, en fin, todos aquellos que viven de y en relación con la selva. Además, la botánica, la etnología, la ecología y la arqueología vienen al encuentro de ese método investigativo, dando como resultado un bricolaje metodológico que, por lo tanto, es necesariamente interdisciplinario y tiene como objetivo dar cuenta de la riqueza de las relaciones entre humanos, plantas, animales, así como de la multiplicidad de seres no humanos que conforman los mundos indígenas.

Todavía no hay informaciones suficientes sobre los pueblos aislados en Sudamérica. En la Amazonía brasileña, particularmente, tales informaciones se obtienen a través de expediciones de monitoreo, de investigaciones de carácter etnográfico y de relatos de los pueblos indígenas y sus vecinos ribereños. Es evidente la necesidad de unir tales perspectivas indigenistas y etnográficas, con el fin de promover un enriquecimiento mutuo que amplíe la imagen que se tiene de estos grupos y, simultáneamente, que contribuya a la implantación efectiva de políticas específicas orientadas a su protección.

Las ramas rotas, semillas descartadas en el entorno de los campamentos, pliegues y torsiones en las hojas de palmeras para la construcción de refugios, utensilios y restos de alimentos presentes en los senderos y campamentos expresan, aunque de manera fragmentada, la historia de la movilidad y de la territorialidad hi-merimã. Temporalidades humanas y vegetales entrelazadas: el ciclo de vida de las plantas, sus estructuras de crecimiento, procesos de regeneración y de cicatrización en sincronía con los desplazamientos, campamentos y prácticas de los grupos hi-merimã. Artefactos afectados por el paso del tiempo también cumplen el papel de vestigios arqueológicos que nos guían a través de la comprensión de la historia y del presente de dichos grupos.

La metodología que proponemos para guiar nuestra mirada entre los bosques hi-merimã está orientada por la socialidad vegetal prominente entre los pueblos arawá (Shiratori, 2018; 2020; Aparício, 2020; Cangussu, 2021; en prensa); por eso, una lectura atenta de sus vestigios arqueológicos y de las singularidades fitofisionómicas de las plantas con las que interactúan, ilumina los relatos de los habitantes del entorno - de los encuentros fortuitos, de las historias del pasado, de los vestigios que resisten en el bosque - y de las referencias bibliográficas 
disponibles sobre el contexto etnográfico. Tal abordaje revela las varias estrategias de sobrevivencia adoptadas por estos pueblos.

Partimos aquí de la rica narrativa de un encuentro fortuito entre dos ribereños y tres mujeres hi-merimã para organizar e iluminar los vestigios de la selva y las narrativas arawá sobre ese grupo aislado, buscando recorrer los senderos entrelazados de quienes siguen estos caminos ${ }^{6}$. El relato de dicho encuentro es el hilo conductor que organiza las notas que analizamos en este artículo; por lo tanto, estas no expresan solamente lo que el señor Domingos nos cuenta, ya que su testimonio viene acompañado de las conversaciones con los Jamamadi y de las expediciones conducidas por los indigenistas de la FUNAI en tierras hi-merimã.

\section{NARRATIVA DE UN ENCUENTRO INESPERADO}

Antes de la homologación de la Tierra Indígena Hi-Merimã, en 2005, la región estaba ocupada por familias de caucheros y patrones del caucho que habían migrado del Nordeste brasileño hace casi un siglo. Algunas estaban asentadas próximas a las áreas de uso indígena y a menudo los senderos de ambos se cruzaban y así se producían los contactos imprevistos. La convivencia en un territorio que empezó a ser compartido estaba basada en la desconfianza mutua que imponía el distanciamiento y la vigilancia constante de los desplazamientos de cada grupo. Mantener una buena distancia se hizo imprescindible para las familias desposeídas de su libertad en los senderos, ahora utilizados por trabajadores del caucho. La narrativa transcrita a continuación (registrada en 2015) ilustra la complejidad de las dinámicas territoriales objeto de análisis del presente texto.

\footnotetext{
Por lo tanto, estas notas se componen de datos que se podrían distinguir entre directos e indirectos, o de primer y segundo orden, primarios o secundarios, una vez que provienen de contextos distintos del trabajo de campo, es decir; en el primer caso, las informaciones han sido recolectadas personalmente en expediciones de monitoreo en el territorio hi-merimã en las que también se encontró vestigios y efectos antrópicos en la selva; en el segundo, a su vez, se tratan de informaciones originadas de entrevistas o informes de terceros. Sin embargo, incluso tal distinción es tenue, pues toda mirada está guiada por otro punto de vista y no solo los humanos actúan en la conformación de estos vestigios (en el caso de los paisajes antropizados y de la formación de nicho). En el contexto de trabajo con los pueblos en aislamiento esa distinción implica un contrasentido, una vez que el acceso directo a ellos nos está interdicto, por lo tanto, toda etnografía con pueblos aislados se hace by proxy.
} 


\section{Figura 1. Área del encuentro}

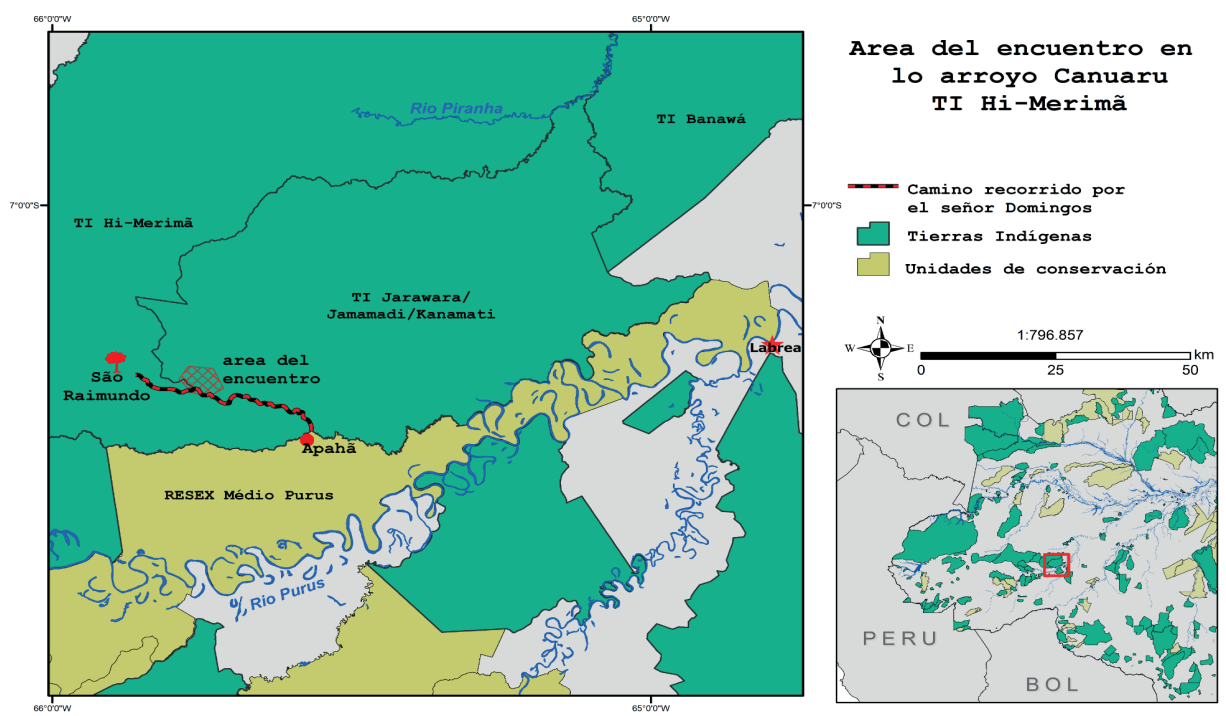

Elaboración: L. Furquim.

Con la presentación de este relato ${ }^{7}$ buscamos profundizar en las sutilezas relacionales que mantuvieron, durante décadas, la proximidad silenciosa y, en la medida de lo posible, oculta entre los hi-merimã y las familias ribereñas. Evidentemente, está lejos de nuestro propósito relativizar la política del no contacto que es, sin lugar a dudas, fundamental en la orientación de la política indigenista hacia los pueblos aislados. Sin embargo, una visión maniqueísta no sería suficiente, tampoco haría justicia a la fragilidad territorial del contexto y a la perspicacia relacional expresada tanto por los indígenas como por los ribereños. Así, el encuentro entre el señor Domingos, su hermano, moradores de la comunidad Apahã, con las tres mujeres y un niño hi-merimã en el río Canuaru (ver mapa) nos permite mirar, en detalle, algunos aspectos de la vida en evitación y desconfianza reciprocas.

Proponemos un análisis de los eventos a través de notas que revelan la centralidad y la fecundidad de las plantas para la comprensión de los hechos narrados. Las notas se encuentran al final del relato. Su elaboración se fundamenta en datos bibliográficos de trabajos antropológicos, arqueológicos y botánicos, así como en las informaciones obtenidas junto a los pueblos indígenas y ribereños del entorno;

7 Relato concedido por el señor Domingos en su comunidad, en el año 2005. 
por lo tanto, una vez más, no se restringen al relato del señor Domingos, quien nos sirve como brújula para señalar la dirección de nuestras reflexiones. Se suman a ellas las informaciones provenientes de las expediciones de monitoreo realizadas por el Frente de Proteção Etnoambiental Madeira-Purus, en el cual uno de los autores actuó como coordinador.

\section{RELATO DEL SEÑOR DOMINGOS SOBRE EL ENCUENTRO.}

El encuentro con las indígenas tuvo lugar hace casi quince años. En ese tiempo mi hermano Carlinhos aún estaba vivo. Sé que el encuentro fue en la víspera del Día de los Fieles Difuntos, ya que Carlinhos y yo habíamos subido la quebrada para prender una vela en donde nuestro padre estaba sepultado, en nuestra antigua ubicación, en las cabeceras del Canuaru, lugar conocido como São Raimundo. Estaba muy seco. Subimos en una piragua ${ }^{8}$. A finales de octubre. El invierno no había empezado. Nuestra provisión consistía en un poco de harina, pues nuestra intención era pasar poco tiempo allá arriba. Salimos temprano del Apahã [nota 1]. Remamos durante dos días seguidos. En la primera noche dormimos en la boca de la [quebrada] Vara. En la noche del segundo día, llegamos a la boca de la [quebrada] Zé Ribeiro. Corría poco el Canuaru. Muy seco. Paramos para mariscar y encontramos un pozo con sábalo. De ahí en adelante estaba muy seco y había mucho charco.

Muy temprano, al tercer día, pusimos la piragua en tierra y seguimos a pie. Caminamos por la orilla izquierda del Canuaru. Al mismo lado de donde acampamos la noche anterior. Muy temprano, en las primeras horas del día, empezamos a ver peces muertos bajando por la quebrada. Sabíamos que los indios estaban pescando con barbasco hacia arriba [nota 2]. Después de algunas horas de caminata, salimos de la vereda de los indios. Era una vereda nueva y llena de quiebres. Una vereda de menos de una semana. El irapay («caranaí») estaba solo acostado, repisado. Los cortes de los palos estaban hechos con un hacha sin filo.

Convencí a Carlinhos de que siguiéramos por la vereda de los indios para ganar tiempo en la caminata, pues el camino ya estaba hecho. No había necesidad de cortar. Carlinhos tenía un poco de miedo, pero sabíamos que no había ningún problema. Esos indios jamás se metieron con nosotros en todo el tiempo que vivimos allí. Seguimos rápido y atentos. Sin hacer ruido [nota 3]. Cerca del medio día encontramos un campamento abandonado. En el campa-

8 En portugués, casquinho, bote construido a partir de la excavación del tronco de un árbol. Esto hace que tales embarcaciones se formen a partir de una sola pieza maciza. 
mento había muchos moquéns [parrilla rústica de madera para ahumar carne], seis chozas y algunos cobertizos. Las pajas que usaron en ese campamento eran de patabá (patauá), bacaba y platanillo. Calculé que el campamento tenía alrededor de un mes. Fue el campamento en donde los indios pescaron con barbasco. Aún había muchos restos de liana. Había un pez muerto en una «camboa». Y pez muerto también en la quebrada. En este punto el Canuaru ya casi no corría, pues estaba muy seco [nota 4]. En el campamento había restos de pecarí barbiblanco, pecarí de collar y tapir. Dejamos el campamento de los indios y seguimos por la vereda.

Después del campamento en adelante, subiendo la quebrada, el camino era muy reciente. Se notaba que los indios habían pasado por allí el día anterior. Seguimos más despacio y muy silenciosos. En determinado punto, la vereda salía de la orilla del Canuaru y seguía hacia el centro de la tierra. Paramos en ese punto. Desde allí se podía escuchar a los indios. Estaban a menos de cien metros de distancia. Hacían mucho bullicio. Hablaban y se reían en voz alta. A partir de ese punto dejamos la vereda de los indios y seguimos nuestro camino hacia la otra orilla del Canuaru. Caminábamos despacio y en absoluto silencio. Aquí y allá veíamos un quiebre nuevo. Ellos estaban desplazándose intensamente por aquella zona. Después de un rato de la caminata, Carlinhos se detuvo súbitamente. Él, que iba adelante, vio a los indios. En realidad, eran tres mujeres y un niño. Ellas al principio no nos vieron. Estaban muy ocupadas excavando el tallo de una papa. Y en ese momento intentamos mantener la calma y ser cautelosos. Sacamos los cartuchos de las escopetas y los apoyamos en el muñón de un palo, fuera de la vista de las mujeres. Permanecimos un rato observando las mujeres excavando la papa. Utilizaban una espátula grande y un hacha mal encabada ${ }^{9}$ [nota 5].

De repente las mujeres se levantaron, hablaron algo entre ellas y se acercaron a nosotros. Ellas no parecían asustadas. Me acuerdo de algunas de sus características. El niño tenía como máximo unos dos años, la mujer mayor tenía alrededor de cincuenta años, y las dos más jóvenes tenían de veinte a treinta años. Tanto el niño como las tres mujeres tenían la piel más blanca que la de los jamamadi que conozco. Creo que la joven de veinte años era la madre del niño. Él parecía no tener ningún corte de cabello, estaba desnudo y se veía bastante saludable. Piel muy tersa y gordito. Ya tenía algunos dientes. No bajó al suelo ni una vez mientras estuvo cerca de nosotros. Cuando dejó el regazo de la señora mayor, pasó a la mujer más joven, que parecía ser su madre. Digo esto pues, cuando la señora pasaba al lado de esa mujer el niño se tendía para pasar la mano en sus cabellos, y sus senos estaban bien hinchados, como si todavía estuviera amamantando.

\footnotetext{
$9 \quad$ Encabar se refiere a la técnica de insertar el cabo en el hacha.
} 
El cabello de la mujer más joven era bien corto. Muy corto. Como nuestro cabello de hombre. Llevaba una falda hecha de envira que la cubría solo por delante. Con un amarre de «mata-matá» en los lados. Pero era ancho y largo. Cubría bien la parte delantera. Ningún amarre en el cuerpo, ningún collar. Usaba un arete. Parecía hecho de miconia (canela de velho), del grosor de un dedo, con aproximadamente diez centímetros de largo. En el labio tenía otro palo de miconia (canela de velho) que le llegaba más allá del mentón [nota 6]. Era gordita y rechoncha, como las jamamadi. La región de los senos hasta los hombros estaba toda pintada. Con unas ruedas moradas. Se percibía que la pintura salía con agua. Tenía la piel recién pintada. Creo que era la ortiga chinipanga o fruta morada. Me acuerdo que las jamamadi se pintaban así en el pasado. Tenían las caderas anchas y piernas rollizas, diferentes de las jamamadi. La piel bien clara. Tenía los labios pintados de color morado. Ojos rasgados, cara redonda, y tenía todos los dientes.

La otra mujer, quien parecía tener alrededor de treinta años, era bien discreta. Quizás estaba un poco asustada con nuestra presencia. Se parecía a la mujer más joven. Pelo corto, la misma falda, el mismo arete y un palillo debajo del labio. También era gordita, pero no tenía pinturas en el cuerpo. Ella también era más blanca que las jamamadi. Los labios estaban pintados de morado y tenía todos los dientes. La señora mayor tenía unas enviras de mata-matá atadas en la espinilla y en ambos brazos. Además de los aretes y del labio con miconia, ella también tenía en la nariz, traspasado de un lado a otro, un palo de unos cuatro dedos de largo. Era más flaca que las otras dos mujeres. También llevaba el pelo corto ya con unos hilos blancos. A ella le faltaban los dientes frontales. Era ella quien sostenía al niño en el regazo con una envira cuando las encontramos, y fue ella la que primero se acercó y nos habló. Señaló el sábalo que Carlinhos llevaba en la mano y dijo: «atixã» (o atxã). Repitió esa palabra un par de veces. Luego dijo algunas cosas señalando las escopetas que estaban apoyadas en el tronco. La mujer mayor se volvió hacia mí y me tocó el brazo. Mientras tanto, las mujeres menores se mantuvieron calladas, mirando todo. Noté que la mujer se llevó la mano a la boca. Creo que probó mi sudor.

Después de eso, la mujer retrocedió un poco y comenzó a hablar y a gesticular sola por casi diez minutos. Me tomé la libertad y fui a donde las mujeres estaban recogiendo la papa. Las mujeres me siguieron. Carlinhos vino por último. Cogí el palo que ellas utilizaban y las imité. Cavé con el palo. La mujer mayor le pasó el niño a una de las jóvenes. Cogió el hacha y empezó a cortar las raíces de la papa. Manejaba el hacha como si fuera un azadón. La cuchilla del hacha era bien nueva, pero estaba sin filo, desafilada e incrustada en un palo torcido. Sacamos la papa de la tierra y la llevamos a un lugar limpio. Era muy grande como para que la llevaran. Quité mi machete del dobladillo, me tomé el riesgo de cortar la papa por la mitad y miré a las 
mujeres. No dijeron nada. Creo que aprobaron mi intención. Corté la papa en dos partes. Quité un par de enviras en un mata-matá cercano y se las di a la mujer mayor. Ayudé a la mujer a atar las dos partes de la papa.

Estaba todo muy en calma. La mujer menor tarareaba una canción en voz baja en su lengua mientras amamantaba al niño. La otra mujer se mantuvo de pie a mi lado. Ella miraba y hablaba unas cosas con la mujer mayor. Carlinhos se sentó un poco apartado, mirándonos. Después de un rato de silencio las mujeres volvieron a charlar. Una de ellas, la menor, que no amamantaba, cogió la mitad de la papa, puso la envira en la cabeza y luego siguió por el camino que habíamos recorrido para llegar allí. Carlinhos hizo un gesto de mano para mí. Me dijo que siguiéramos nuestro camino. Cogimos las escopetas, nuestro pez, y seguimos nuestro camino por la ribera del Canuaru. Las mujeres nos siguieron por algunos minutos. La otra mitad de la papa se quedó allí. En cierto momento las mujeres hablaron entre sí. La mujer que llevaba el niño también decidió regresar. La mujer mayor gesticuló para nosotros. Creo que ella quería que las acompañáramos al lugar en donde estaban los otros de su grupo. Hacia la misma dirección en donde habíamos escuchado el bullicio de los indios charlando hace algún tiempo. Señalé el sol y seguí con la mano su movimiento. Intenté explicarle que íbamos a volver en tres días. Así seguimos nuestro camino. Después de unos minutos notamos que la mujer nos seguía. Nos acompañó durante mucho tiempo. A veces ella se quedaba atrás. Cuando volvía a acercarse a nosotros, llevaba unas ramas y hojas. En algún momento estaba toda pintada. Tenía la boca y las manos coloreadas con pintura morada [nota 7]. No entendíamos por qué ella nos seguía.

Entonces decidimos parar y armar el campamento. Todavía era temprano. Pasaba de una de la tarde. Carlinhos se fue a preparar el sábalo. Yo prendí el fuego. La mujer nos ayudó a limpiar el sitio del campamento. Ella cogió unas pajas de azaí nuevo y con las manos hizo su lecho en el suelo. Me quité el sombrero por la facilidad con que rompió las hojas con solo una de las manos. Hizo un pliegue y las trenzó de un modo distinto, las recogió con mucha facilidad. Cuando el pez quedó listo, ella recogió más paja y la dispuso en el suelo. Carlinhos no le echó sal al pez. Puso el pescado asado sobre la paja. Al lado puso la sal y la harina y empezó a servirse. Ella no quiso la sal. Pero comió el pescado con un poco de harina. No comía la harina como nosotros. Ella la echaba un poco sobre el trozo de pescado antes de comer. Bien despacio. Como si no conociera la harina. Después de almorzar decidimos seguir nuestro camino. La mujer fue con nosotros. Caminamos más de tres horas. En este punto ya estábamos preocupados con la mujer que nos acompañaba. Encontramos una choza muy vieja y decidimos acampar allí. Ya no estábamos lejos de São Raimundo, nuestra antigua residencia. Pensamos que, si ella decidiera volver a su campamento, habría tiempo suficiente. Pero ella 
quiso permanecer con nosotros. Con su ayuda, encontramos un sitio para que durmiera. Incluso le ofrecí mi hamaca. Ella no la aceptó. Ella hizo su propio cobertizo y cubrió el suelo con pajas de tagua (jarina). Hicimos una hoguera.

En un cierto momento me senté en la hamaca y empecé a quitarme unas espinas de mis pies con el machete. La mujer se acercó y empezó a quitarse las de ella también. Ella me señaló una zona de su pie. Quería mi ayuda para sacarse la espina con el machete. Le quité algunas espinas grandes de su pie. Nos bañamos en quebrada. Ella no se bañó. Cenamos otro sábalo. En algún momento ella hizo un recipiente con paja de irapay (caranai) y nos lo regaló. Carlinhos entendió que ella quería agua. Él buscó agua y se la dio. Nos acostamos en nuestras hamacas. Ella se acostó en el lecho que hizo en el suelo. Alrededor de las diez de la noche, Carlinhos me llamó y me dijo que la india se había ido. Había dos tizones al lado de su lecho.

En la mañana del día siguiente hicimos una breve expedición por el sendero que habíamos recorrido el día anterior y nos detuvimos en un hormiguero. Ahí vimos las huellas de su regreso. Probablemente ella utilizó una leña encendida para poder caminar en la oscuridad de la noche [nota 8]. Seguimos nuestro camino hasta São Raimundo, sitio ubicado en la orilla izquierda del río Canuaru. Llegamos el 2 de noviembre. Encendimos una vela por nuestro padre, Raimundo Pedro de Souza. Aún había muchos árboles fructíferos allí. Muchos chontaduros y árboles castañeros. Se notaba que muchos indios frecuentaban aquel lugar. Habían tumbado algunas palmas y castañeros [nota 9]. Regresamos temprano, en la mañana del tercer día. En la vuelta nos desviamos del camino que habíamos recorrido en la ida para no encontrarnos nuevamente con los indios. Llegamos a nuestra piragua al final de la tarde y decidimos concluir el regreso aquella misma noche, remando despacio y en silencio.

\section{NOTAS BOTÁNICAS}

\section{Nota 1. Relaciones inesperadas: ribereños e indígenas en Mamoriazinho}

Domingos es un ribereño residente en la comunidad de la boca de Apahã, en el río Mamoriazinho, un afluente del margen izquierdo del medio curso del río Purus. Como muchos otros de la región, proviene de una familia de migrantes que dejó Ceará motivada por las promesas del caucho en la Amazonía. Sin embargo, endeudados compulsoriamente con los patrones del caucho, Domingos y su familia se vieron arrastrados a un régimen de esclavitud en los cauchales. Así, sin otras alternativas, empezaron a trabajar como extractivistas: copaiba, sorbo, castañas y cazas, sobre todo de pieles de felino, denominadas «fantasías» en Brasil, 
Figura 2. Dueña Inês y el señor Domingos Costa de Souza
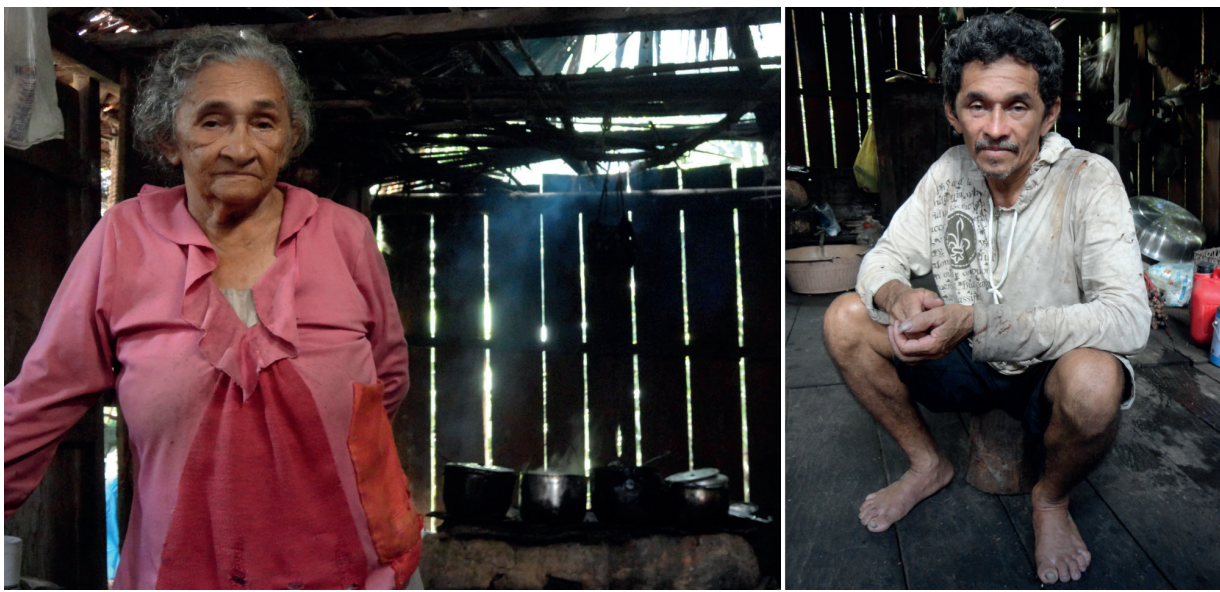

Foto: D. Cangussu/2015.

las cuales eran muy valoradas en su tiempo. Estos fueron los principales productos extraídos de la selva, comercializados a precios insignificantes a los patrones y regatones, personajes del proceso de colonización de toda la región amazónica. La antigua localidad de São Raimundo, donde han vivido Domingos y su familia, actualmente está ubicada en el interior de la Tierra Indígena Hi-Merimã, demarcada oficialmente en 2005. Concluido el proceso de remoción de no indígenas, la familia de Domingos se trasladó a la quebrada Apahã, que actualmente integra la Resex (Reserva Extractivista) Médio Purus. En el reporte de Identificación y Delimitación de esa tierra indígena, Pohl (2000) transcribe el siguiente testimonio de Dueña Inês, madre de Domingos, muerta en 2018:

Crie a todos mis hijos en el sudor del caucho, ¡los que me conocen lo saben! Vine de Ceará. Vivíamos en Abureté. Yo tenía nueve años. Cuando vinimos, era el tiempo de los emigrantes [sic]. [...] Éramos los soldados del caucho, arigó ${ }^{10}$. En el inicio nos llamaban bravo, solo llamaban bravo, pero mi padre ya estaba habituado al Amazonas. Él trabajaba en el Amazonas, pero volvía a Ceará, y así vivía hasta que nos trajo [...]. El que tenía residencia aquí era Antônio Adolfo y Pedro Veriço, que ya vivían aquí. Nosotros construimos una casa, nos faltaba incluso la harina. Mi hijo murió por falta de harina, ahí todo se acabó.

10 Arigó: nombre de un pájaro migratorio que acabó por designar a los inmigrantes provenientes de Ceará, estado del Nordeste brasileño, quienes constituyeron el principal flujo migratorio durante el ciclo del caucho en la Amazonía. 
Estos trabajadores ingresaron a los territorios indígenas y, con ellos, volvieron las enfermedades y los conflictos sangrientos, razón por la cual este fue también un período marcado por el acentuado despoblamiento de los pueblos indígenas de la región. El río Mamoriazinho, por donde muy probablemente habrían llegado los primeros blancos al territorio de los jamamadi en busca de caucho y sorbo, también es llamado como Fakuma, es decir, río del dolor, en alusión directa a la historia de epidemias y masacres que marcaron la región.

La narrativa presentada por Domingos se desarrolla en el interior del territorio hi-merimã, muy probablemente con algún pueblo madi (hablantes de las lenguas madi, familia arawá) ubicado en el interfluvio del medio Cuniuá/Purus. Estos grupos madi tradicionalmente se organizan en pequeñas agrupaciones con un frecuente patrón de movilidad (Mendes dos Santos, 2016; Shiratori, 2018; Aparício, 2019). En los relatos históricos de los viajantes y en los primeros registros etnográficos de la región, se aplicaba el término jamamadi, de manera genérica, a todos los pueblos que habitaban, principalmente, las tierras firmes no inundables, evitando las riberas y los cursos de agua más caudalosos. Menos que un etnónimo, jamamadi era una calificación inclusiva, aplicada a las innumerables agrupaciones pequeñas que vivían en los bosques; de ese modo, los jamamadi, los banawá — en el pasado denominados jamamadi do Apituã —, los jarawara, los hi-merimã y, además, en el alto Purus, los sivakoedeni y los jamamadi madiha eran todos identificados bajo el mismo término: «jamamadi».

Dixon (2004) adoptó la etimología sugerida en el inicio del siglo XX por Steere, quien consideraba que el término jamamadi estaría compuesto por dos palabras: yama, «matorral», y madi, «persona», derivación fonética de la expresión jiwã-mãgi, equivocadamente atribuida a un origen paumari, y cuyo sentido sería «hombre del matorral». Esta es una hipótesis frágil, toda vez que yama (o zama) en las lenguas madi es un pronombre indeterminado - como it en inglés-y madi un colectivizador o pronombre personal. Dicho esto, una posible traducción del etnónimo jamamadi sería simplemente «gente».

Actualmente, el etnónimo [jamamadi] contempla los remanentes de algunos grupos hablantes de dialectos de la misma lengua madi, y que vivían en el área comprendida por el interfluvio entre el río Piranha, la quebrada Mamoriazinho (denominado como Mamoriá Mirim en algunos relatos) y el río Purus. En el contexto de estos pueblos, los más mencionados son: los hawa, de la quebrada Aripuanã; los nakanike, de la quebrada Sabuhã; los boti, de la quebrada Mamoriazinho; los wayafi, de Apaha; los kosiba, del río Curiá; los hi-merimã, del alto Riozinho y del Mamoriazinho (Shiratori, 2018). 
Sobre los subgrupos madi, también conviene mencionar el sistema onomástico vegetal empleado en ese contexto etnográfico (Shiratori, 2018). El subgrupo hawa está asociado a la palma patabá, hawa (Oenocarpus bataua), tal como los kosiba al babasú, kosi (Attalea speciosa); los boti, a la shapaja, boti (Attalea phalerata); los wayafi, a una especie de la familia de las miristicaceae, waya (Iryanthera spp.), utilizada por los demás grupos arawá en la confección de cerbatanas. En ese sistema de denominación de los grupos madi, los propios hi-merimã, según los jamamadi, estarían asociados a un árbol del género Cecropia sp.

En el proceso de remoción de las familias no indígenas, Domingos y su familia dejaron la localidad de São Raimundo y se fueron a vivir en Boca do Apahã. Sin embargo, hay que considerar que Apahã es un territorio tradicionalmente ocupado por los wayafi, uno de los subgrupos madi. En el diálogo con Berinawa (Gasparino Jamamadi), un importante líder wayafi fallecido en 2019, él relató que en las cabeceras del Apahã todavía hay grandes pedazos de warakana que han sido enterrados por su abuelo Afi antes de que dejara la región debido a los conflictos. Warakana es una cera producida a partir de la resina del árbol brea-caspi (Symphonia globulifera). Esa resina, o cerol, como es popularmente conocida entre los ribereños, es utilizada por diversos grupos indígenas para fijar e impermeabilizar la cinta de envira a lo largo del cuerpo de la cerbatana o para encerar hilos, que se vuelven impermeables y más resistentes. Muchos pueblos amazónicos utilizan la savia de S. globulifera en la producción de resinas. Sin embargo, la receta de los jamamadi para su fabricación es mucho más elaborada. Además de la leche amarilla típica, ingrediente principal, también se utilizan las savias lactescentes de leche-caspi (Couma macrocarpa) y de la liana de un árbol llamado sabano por los jamamadi.

Figura 3. Warakana producida por Berinawa Jamamadi

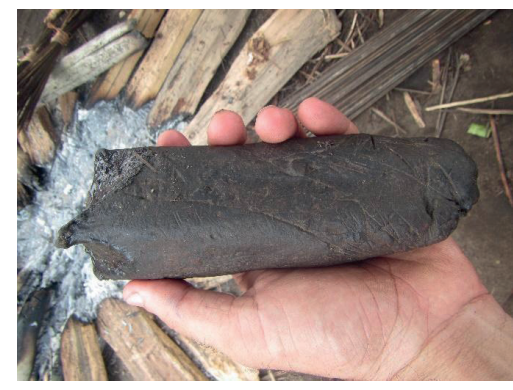

Foto: D. Cangussu/2017. 


\section{Nota 2. Plantas venenosas en la cosmología madi}

En la desembocadura de la quebrada Canuaru se instaló una de las tres bases de coordinación del FUNAI, departamento responsable por la vigilancia y protección de la Tierra Indígena Hi-Merimã. En esta base se realizan actividades de vigilancia del sector sur de ese territorio indígena, con funcionarios y materos colaboradores del órgano indigenista, algunos de ellos indígenas jamamadi de la Tierra Indígena Jamamadi/Jarawara/Kanamati. Los relatos sobre peces muertos que descienden por el lecho seco de los ríos Canuaru y Mamoriazinho son muy comunes en esta región, especialmente entre los meses de agosto y octubre, el apogeo del verano amazónico, período de sequía y una marcada disminución en el volumen de los cursos de agua. Los peces muertos sugieren una intensa actividad pesquera de los hi-merimã en lo alto de estos ríos y sus afluentes. Esta modalidad de pesca utiliza ictiotóxicos/piscicidas, plantas que tienen compuestos capaces de envenenar peces que, una vez entorpecidos, se capturan fácilmente (Brewer-Carías, 2013).

En este contexto etnográfico, la especie más utilizada es el kona/kunaha (Deguelia utilis), popularmente conocida como barbasco (timbó en Brasil). Inicialmente, la técnica consiste en construir una presa con varillas en el lecho de la quebrada en donde se hará la pesca. Se cortan secciones de la raíz de D. utilis y luego se las llevan al lugar de la pesca. Se elige un punto más allá de la presa para «bater o timbó», es decir, realizar un procedimiento que consiste en macerar las raíces en la orilla de la quebrada para que su jugo lechoso baje por las aguas y sofoque los peces. Muertos o aturdidos, se captura a los peces durante la pesca o ellos son retenidos en la presa de varillas para su posterior recolección. Ya se han registrado presas de pesca confeccionadas por los hi-merimã en lo alto curso de ambos ríos, Mamoriazinho y Canuaru, así como en la propia quebrada Vara, mencionada en el relato. Esta modalidad de pesca se realiza solo en los tiempos de sequía. D. utilis es ampliamente cultivada por algunos pueblos de la región, tales como los jamamadi y los banawá.

Hay otros ictiotóxicos utilizados por los pueblos habitantes del Purus. Los paumari y apurinã emplean la savia de la catahua amarilla (Hura crepitans) en sus pescas en grandes lagos o, también, para sacar cardúmenes ocultos en la canarana, una hierba originaria de las márgenes del Purus. Los paumari también usan la Ryania speciosa para capturar caimanes (Prance, 1986). Además de la $D$. utilis, se cultivan otros dos ictiotóxicos en los huertos de los suruwaha, pueblo vecino de los hi-merimã y jamamadi: bakiama (Clibadium sylvestres) y mama (Manihot esculenta). Las mujeres suruwaha producen pequeños cebos macerando 
las hojas de bakiama, larvas de hormiga y masa de yuca no exprimida; con la masa se hacen pequeñas bolitas para utilizarlas en pozos y lagunas. Después de la ingestión de los cebos, los peces quedan aturdidos por algunos segundos, momento en que son capturados.

Otra especie de barbasco menos tóxica, utilizada por los madi en sus pescas, es el mamatafo (Deguelia urucu), regionalmente conocido como timbó vermelho (barbasco rojo). Esa planta está presente a lo largo del Canuaru y Mamoriazinho y en gran parte de los arroyos y pequeños cursos de agua de esa región, donde crece en estrecha asociación con otras especies, tales como las palmas patabá (Oenocarpus bataua), bacaba (Oenocarpus mapora) y azaí (Euterpe precatoria). Mientras la presencia de las palmas en estos contextos se explica por la disposición de las semillas de los frutos recolectados en el entorno y llevados hasta el campamento para su consumo, la presencia del mamatafo y del kona muy probablemente se deba al enraizamiento de secciones de la planta que no han sido completamente maceradas durante la pesca.

Figura 4. Mamatafo (Deguelia urucu) a la izquierda y patabá (Oenocarpus bataua) a la derecha de la foto en las orillas de la quebrada Canuaru

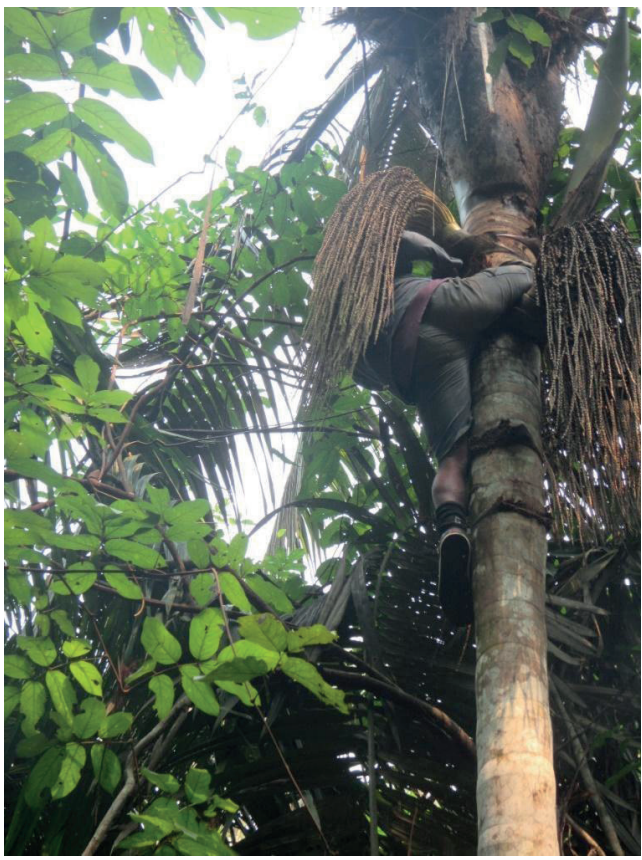

Foto: D. Cangussu/2018. 
Todo el contexto etnográfico arawá está fuertemente asociado al uso y la manipulación de venenos vegetales (Prance, 1986; Huber, 201; Shiratori, 2018, 2020; Aparício, 2019). Es posible observar la formación de nichos culturales (Smith, 2012) como parte de la integración entre las actividades de manejo vegetal y de la pesca, entre otros. La presencia de plantas arbustivas no comestibles aún es poco considerada en estudios sobre la formación de nichos culturales y paisajes domesticados, en virtud del desconocimiento sobre sus usos y de su baja visibilidad florística (Levis et al., 2018). Este caso es una invitación para que la ecología histórica amplíe su espectro de análisis sobre los bosques indigeneizados (Balée, 2008).

Finalmente, hay que considerar el hecho de que el chamanismo vegetal (Shiratori, 2018), centrado en los venenos de las plantas, es una característica notable en las etnografías arawá. De esta forma, aunque se constate este uso explícito en los ambientes antropizados de este contexto presentado, planteamos como hipótesis que el uso, en este caso en la pesca, no es suficiente para explicar la presencia de tales plantas venenosas en los campamentos y chozas arawá.

\section{Nota 3. Interacción y lectura de los vestigios antrópicos}

Durante toda su infancia, Domingos recorrió los caminos y senderos de los hi-merimã, visitando campamentos abandonados y encontrando vestigios dejados por sus vecinos indígenas. Los hi-merimã, a su vez, ciertamente acompañaron a distancia el desplazamiento de los blancos por sus tierras. Alejándose, desde que fuera posible, de las áreas más violentas y marcadas por epidemias, construyendo tapagens, palabra que designa los bloqueos hechos en los senderos por los pueblos indígenas, los cuales funcionan como una advertencia para que los otros no sobrepasen dicho bloqueo en sus caminos principales. En otros casos, las advertencias se transformaban en silbidos y golpes en las sacopemas, extensiones tubulares del tronco de los árboles que, una vez golpeados, emiten sonidos de baja frecuencia escuchados a grandes distancias. La convivencia de Domingos y Carlinhos con los vestigios les permitió una lectura precisa de aquel contexto. La capacidad de reconocer y fechar los senderos indígenas es una habilidad esencial, desarrollada a lo largo de años de vivencia en los bosques. Los senderos que atraviesan las densas colonias de irapay «caranaí» (Lepidocarium tenue), características de los bosques del sur de Amazonas, desafían los materos más experimentados. Sus tallos - los peciolos de esa pequeña palmera - se retuercen y no son completamente seccionados, así demoran meses en secarse y pudrirse. En estos contextos, se consideran otros elementos del paisaje con el fin de fechar adecuadamente el sendero. 
Figura 5. Sendero hi-merimã

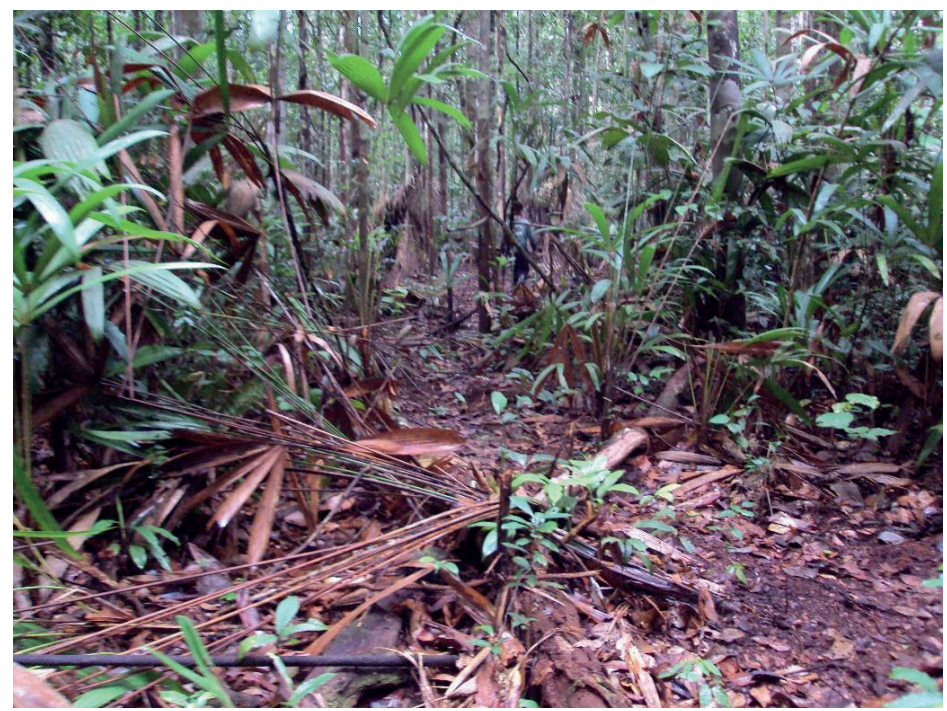

Foto: Acervo de FPE Madeira-Purus/2013.

En cuanto a la presencia del hacha entre los hi-merimã, con seguridad puede ser resultado de algún robo realizado en campamentos de caucheros y extractores de copaiba que persistían trabajando en sus territorios incluso después de la conclusión del proceso de demarcación de las tierras y remoción de los blancos. La historia geológica del interfluvio del curso medio Juruá lo convirtió en un territorio casi sin rocas. No hay piedras adecuadas para la producción y afilado de herramientas líticas en la margen izquierda del medio Purus. Las herramientas de acero de los hi-merimã están siempre sin filo, tal como comprueban los cortes observados en los árboles. Es interesante notar que, si bien los hi-merimã realizan talas selectivas en el bosque, concentradas sobre todo en árboles frutales y palmeras, prácticamente no hay talas próximas a sus campamentos. A menudo los troncos de los árboles vivos se emplean como pilares de sus casas, así como los troncos de los árboles más delgados, en general utilizados en la construcción de moquens, en donde no hay necesidad de cortar los árboles.

Nota 4. La dinámica de los campamentos y el enriquecimiento de los bosques

Los hi-merimã prefieren construir sus campamentos cerca de quebradas de su territorio. Su habitación preferida en los tiempos de sequía son los «rabos de 
jacu», un cobertizo muy rústico y de fácil construcción. En general ubicados en las tierras bajas de los pequeños cursos de agua, estos campamentos son muy utilizados en las pescas colectivas durante los meses más secos del año. El periodo extendido de la sequía refleja la simplicidad de la cobertura. Los «rabos de jacu» se confeccionan con la disposición de las hojas de palmeras en el suelo, sostenidas por una viga de soporte. Las vigas se construyen con varillas y lianas. La inclinación de las hojas pinnadas, característica de las especies más comunes en la creación de estos campamentos, actúa como un canalón contra el agua de la lluvia y el rocío nocturno. En algunos casos, estos campamentos reciben un acabado con hojas de platanillo (Phenakospermum guyannense). La patabá (Oenocarpus bataua), la bacaba (Oenocarpus mapora) y la maripa (Attalea maripa) son las palmeras más utilizadas en la confección de los «rabos de jacu» por los hi-merimã, con énfasis en la patabá, especie manejada por ellos y que figura entre las palmeras hiperdominantes de la Amazonía (Steege et al., 2013, Levis et al., 2017). La confección de estos campamentos de verano depende, en general, de la disponibilidad de estas palmeras, por lo tanto, se debe considerar su concentración en la elaboración de estrategias de protección de ese territorio.

Los campamentos de invierno de los hi-merimã, a su vez, son mejor elaborados y resistentes a las lluvias torrenciales. Son construidos en lo alto de las tierras firmes, distantes de la zona de inundaciones de las quebradas. Su modelo de construcción es del tipo «cobertizo de dos aguas». El techo se hace con «panos de caranaí» («telas de irapay/caraná»), como se conocen regionalmente las estructuras confeccionadas con las hojas de Lepidocarium tenue. Las hojas y pecíolos de tales palmeras son trenzados y tejidos a lo largo de las secciones del estipe o varillas. Tales secciones, una vez encajadas unas sobre las otras, ofrecen una cubierta sellada. Luego de su secado, las hojas del irapay/caraná (caranaí) asumen una coloración brillante muy característica, como si estuvieran barnizadas. A través de esa técnica también los suruwaha cubren sus malocas de aproximadamente 15 metros de altura y 30 metros de diámetro.

Mientras los campamentos de verano revelan la intensa actividad pesquera, las prácticas orientadas al procesamiento de los frutos de las palmeras, sobre todo los de patabá, bacaba y azaí, son más comunes en los meses de lluvia. Los frutos se procesan en morteros confeccionados a partir de la cáscara del azúcar huayo (Hymenea parvifolia). Las semillas de estas palmeras se dispersan en las cercanías de los campamentos. Al trasladarse hacia otra quebrada, los hi-merimã abandonan un ambiente enriquecido con varias palmeras y árboles fructíferos, una práctica que influye sustancialmente sobre la población de tales especies en su territorio. 


\section{Figura 6. Plántulas de patabá (Oenocarpus bataua) cerca de un campamento de los hi-merimã}

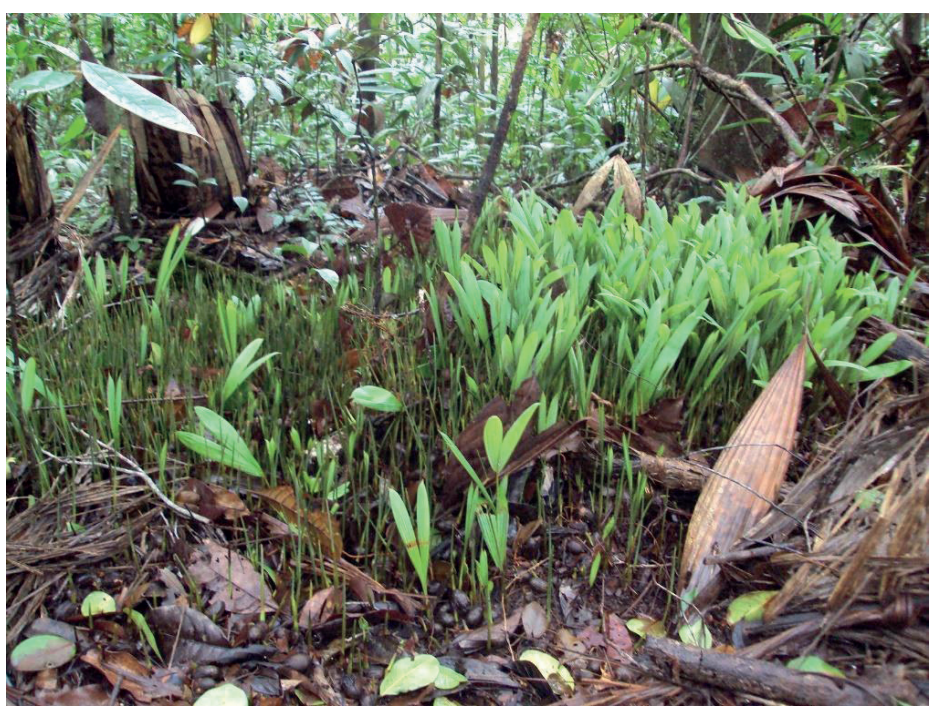

Foto: colección de FPE Madeira-Purus/2018.

Es interesante notar que la formación de nichos enriquecidos se realiza a través de la acción de pueblos indígenas no agrícolas, con un patrón intenso de movilidad territorial. Politis (1996) ha descrito una situación semejante con relación a los grupos nukak del río Guaviare, subrayando la peculiaridad de un sistema productivo de palmeras como el chontaduro (Bactris gasipaes), basado en la «producción a través de la movilidad». La reproducción de ese comportamiento, teniendo en cuenta la predilección de ocupación de áreas sin campamentos previos o huertos ya conocidos (que evitan debido a la proximidad con los enterramientos) sugiere que las zonas de ocupación no se establecen en áreas vegetales enriquecidas: ellos solo las utilizan como puntos de recolección, y así recrean constantemente nuevos «huertos». Partiendo de lo anterior, resaltamos que la «recolección» es una actividad mucho más compleja que la mera búsqueda de frutos, castañas y otras plantas, ella es parte de un proceso productivo que implica territorialidad, movilidad, planificación y creación de nichos. Como los nukak, la práctica hi-merimã se refleja en el desarrollo de un sistema productivo basado en la movilidad, a través de la creación de bosques enriquecidos, el manejo de tubérculos y árboles fructíferos, además del uso de recursos vegetales con distintos fines no alimentarios que dejan sus huellas en el bosque. 
Nota 5. Casimirella ampla: actualización sobre el uso y manejo de plantas de los bosques y rozados

La patata mencionada en el relato muy probablemente es la raíz tuberosa de la planta Casimirella ampla, una liana de la familia Icacinaceae, conocida entre los jamamadi como yamo, y entre los suruwaha, como zamahu. Viajantes que pasaron por la Amazonía en el siglo XIX, siguiendo el ejemplo de Richard Spruce, notaron la importancia de esta patata para los pueblos de la región (Spruce, 1851). Los campamentos hi-merimã observados contienen diversos vestigios de la utilización de esa planta, lo que sugiere su gran relevancia en su dieta. A partir de los relatos y vestigios es posible suponer que las patatas son recolectadas y llevadas hasta los campamentos, donde las rallan utilizando la raíz de la pona (Socratea exorrhiza). La masa que se obtiene de ella es altamente tóxica, por lo que se somete a sucesivos procedimientos de lavado (Ribeiro, 2018). El líquido derivado del lavado de la masa se pone en reposo para permitir la decantación de la fécula, que se someterá a otras etapas alternadas de lavados y periodos de reposo hasta que todo su veneno se elimine de la fécula. Por fin, se desecha su bagazo, lo que genera un gran volumen de residuos de ese material en las cercanías de los campamentos. Se consume la fécula con carnes de caza o pescado; también se emplea en la elaboración de «panes» y masas vegetales. Durante una de las expediciones realizadas en el año 2016, fue encontrado un pequeño pedazo de masa en las cercanías de un campamento. El análisis bromatológico de los granos de almidón presentes en ese bloco reveló que se trata de una masa vegetal formada a partir de la fécula de diversas plantas, entre ellas, la Casimirella ampla (Mendes dos Santos et al., 2021).

El indigenista Rieli Franciscato, fallecido en 2020, participó directamente en el proceso de demarcación de la Tierra Indígena Hi-Merimã. En los comentarios compilados en los reportes de las expediciones que organizó en el territorio de ese pueblo aislado, Rieli afirma que el destino del veneno extraído de la Casimirella ampla no se limitaba a la eliminación, una vez que la presencia regular de la masa de patata en los campamentos de verano sugería que también utilizaban la planta como ictiotóxico, e incluso como uno de los ingredientes de la receta del curare hi-merimã.

La Casimirella spp. ha sido descrita entre otros grupos indígenas como un alimento común en períodos anteriores al contacto. Los mura del bajo curso del río Madeira, por ejemplo, afirman que la patata manhafã era muy consumida en el pasado y aún hoy sirve de referencia para el reconocimiento de los sitios 
Figura 7. Daniel Hi-Merimã recolectando una Casimirella ampla

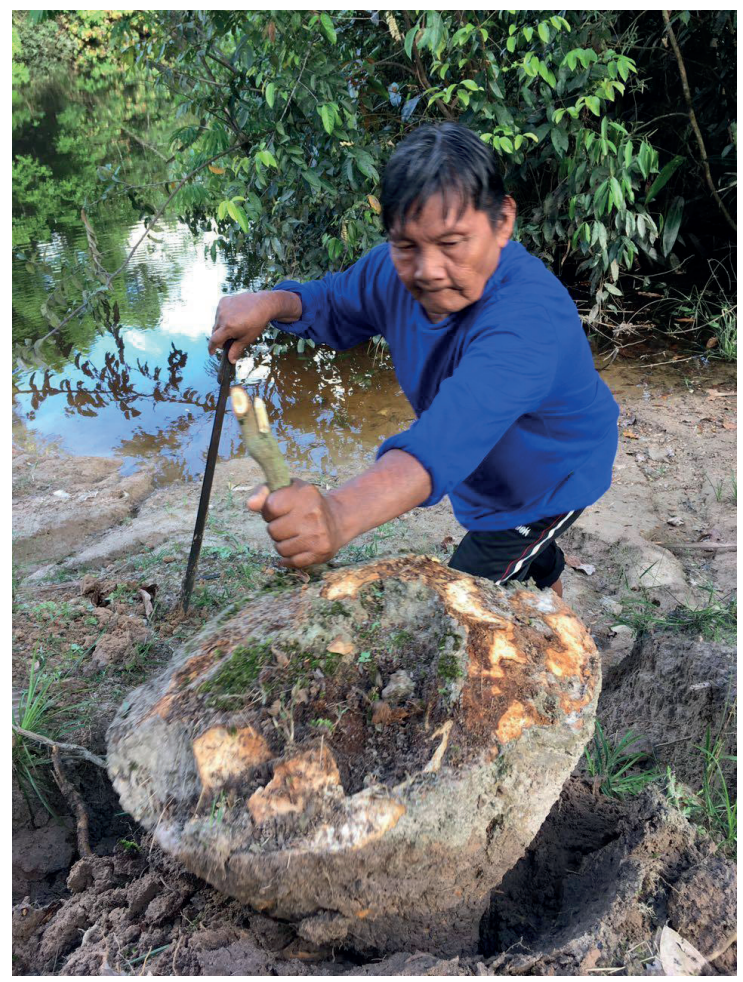

Foto: Elizabeth Miguel/2018.

ancestrales (Amoroso, 2020). Incluso los jamamadi afirman que antes de la época de los patrones del caucho, no conocían la yuca y hacían sus beijus grolados ${ }^{11}$ con la masa del yamo y de otros varios frutos y semillas del bosque.

La presencia de las mujeres en el relato puede no ser un caso fortuito. Es probable que la práctica de la recolección de esas patatas por los hi-merimã sea una actividad esencialmente femenina. Se debe tener en cuenta que las actividades de recolección de yuca en rozados entre los demás pueblos arawá de las tierras firmes también están fuertemente vinculadas con las mujeres. El cultivo de la yuca puede ser una continuidad de esa tradición o una actualización de la recolección de estos tubérculos.

11 Beiju grolado: una torta indígena, del guaraní mbeyú, masa extraída de la yuca y rica en fécula. 
Nota 6. El uso de las fibras vegetales y las cicatrices arbóreas

El mata-matá es el nombre que se le atribuye a diversas especies de árboles del género Eschweilera sp. en la Amazonía y, así como otras especies de la familia Lecythidaceae, tiene una corteza formada por fibras enterizas que se extienden a lo largo de los troncos de los árboles. Estas fibras, una vez destacadas de los troncos, son popularmente conocidas como enviras o embiras. Esto hace que la mayoría de Lecythidaceae sean genéricamente denominadas como envireiras. El proceso de extracción de la envira empieza con un corte inicial en el tronco del árbol. Hay especies cuyo floema fibroso (el tejido de las plantas de donde se extrae las fibras de la envira) es muy superficial, en otras, el proceso demanda la extracción del súber o corteza, el tejido de protección mecánica más superficial e impermeabilizante de la cáscara de los árboles. El corte necesariamente debe exponer las fibras del floema. Hecho esto, se quita la fibra con las manos, de abajo hacia arriba si se desea extraer largas secciones de envira que pueden alcanzar la propia longitud del árbol, o de arriba hacia abajo si se pretende extraer secciones más pequeñas.

Figura 8. Detalle de la cicatriz presente en la cáscara del huwi (Eschweilera amazonica)

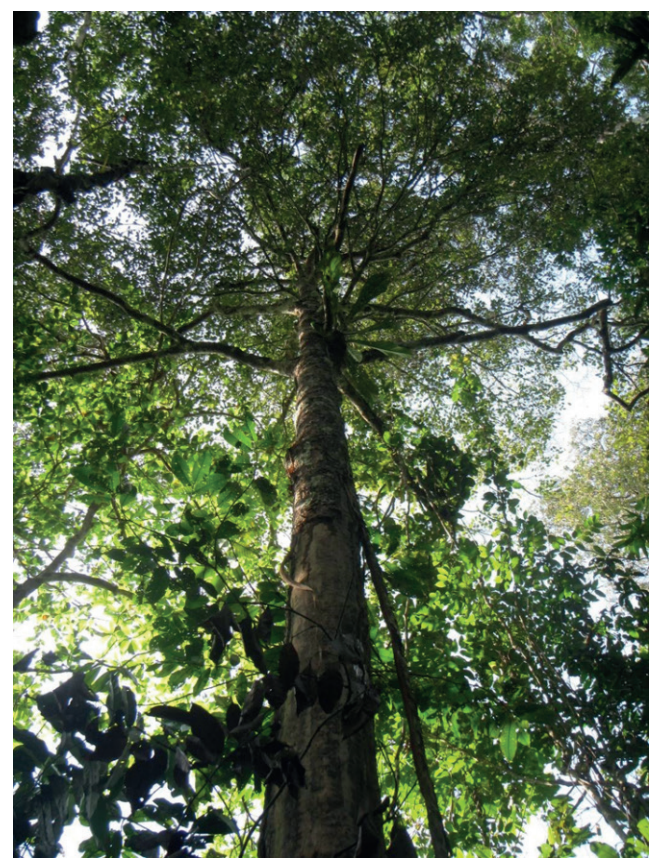

Foto: D. Cangussu/2018. 
Envireira-preta (Bocageopsis multiflora), envira caju, (Onychopetalum periquino) y las envireiras del género Xylopia, Unonopsis e Guatteria, pertenecientes a la familia Annonaceae producen enviras de mejor calidad, más anchas, más resistentes y suaves. Las envireiras más abundantes pertenecen al género Eschweilera, o sea, los mata-matá (cargueros). Las enviras son muy utilizadas por los pueblos indígenas de la Amazonía para distintos fines. Las hamacas suruwaha, por ejemplo, son confeccionadas preferentemente con las fibras de Eschweilera amazonica.

Figura 9. Las jóvenes suruwaha wikia, hibumu y tiabariu bañándose en la quebrada Jukihi vestidas con faldas de envira

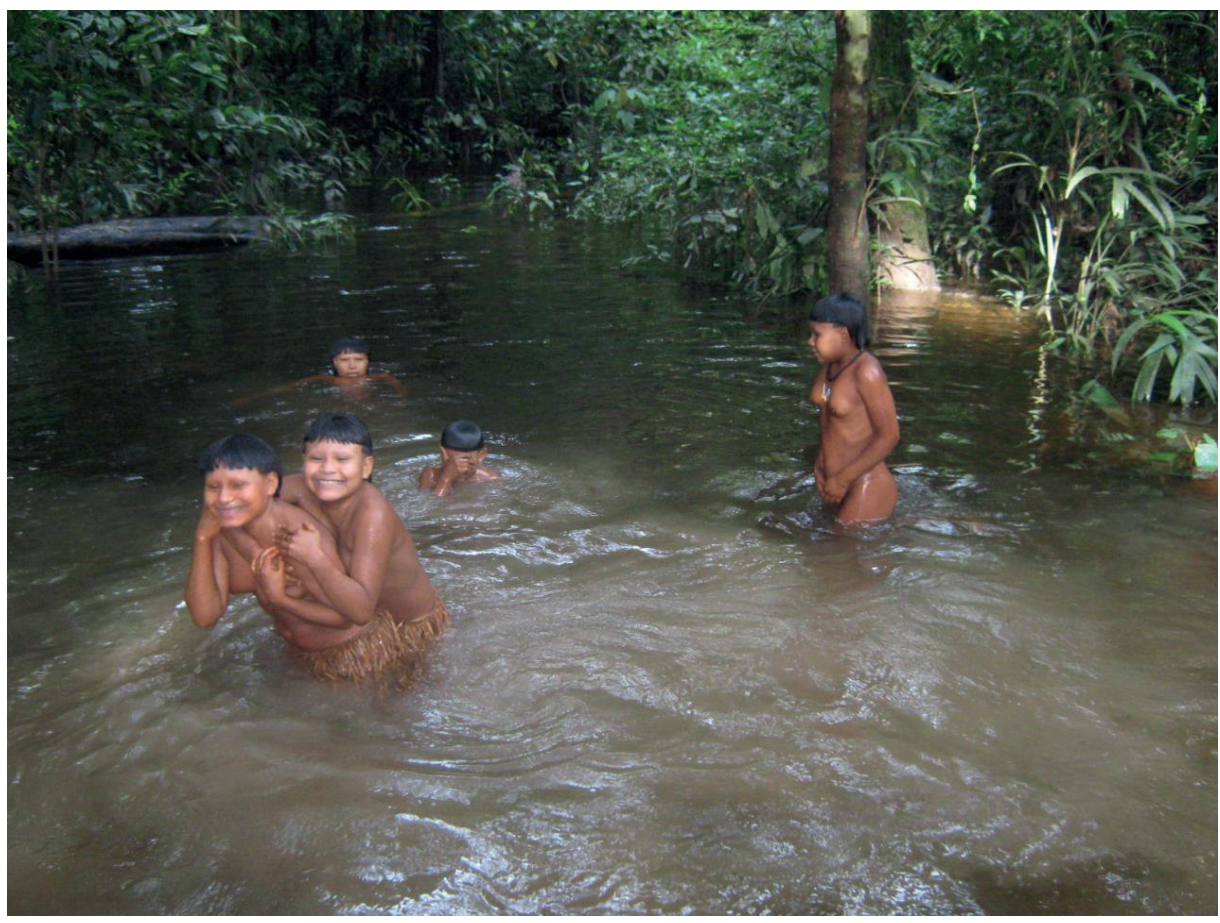

Foto: Adriana Huber $/ 2009^{12}$.

12 Inspiradas por una película sobre otros pueblos indígenas, en 2009 algunas jóvenes suruwara decidieron producir y utilizar faldas de envira, muy semejantes a las usadas por las mujeres hi-merimã y jamamadi, pero muy distintas de las tradicionales sukwady suruwaha de algodón teñidas con achiote. «Eso fue solo una diversión. Una moda efímera entre ellos» (comunicación personal de Adriana Huber). 


\section{Nota 7. Palabras invasoras y los colores de la agrobiodiversidad arawá}

En el relato de Domingos, es evidente el intercambio de palabras entre las distintas lenguas habladas en el Purus. Cuando se refirió al pez que Carlinhos llevaba consigo y pronunció repetidas veces la palabra atixã, probablemente una derivación fonética de la palabra matrinxã (sábalo), la mujer mayor hi-merimã revela el conocimiento de la lengua del invasor y relativiza la categoría de «aislados», tan llena de equívocos y malas interpretaciones. Las mujeres hi-merimã conocían no solo algunos aspectos de la lengua de los ribereños sino también los hábitos de los hombres, sus viviendas y herramientas. Sin duda, sabían que eran miembros de la familia que hace poco habitaba un área más alta del Canuaru, quizás fue por eso que las mujeres hi-merimã se acercaron.

Por otro lado, Domingos señala a la planta chinipanga como la responsable por la pintura utilizada por las mujeres. Más que la precisión de la identificación botánica, es interesante notar que el término utilizado proviene de la lengua quechua y que se refiere a la planta ortiga (Urera spp.). En quechua, chini: ortiga, panga: hoja (Doyle et al., 2013). Aparentemente la palabra matrinxã se desplazó río arriba, llevada por los colonizadores oriundos del Nordeste brasileño, mientras que la palabra chinipanga, derivada del alto Purus, bajó el río con los caucheros peruanos o los pueblos aruak, vecinos de los quechua. Esta es solo una hipótesis, toda vez que no hay registros del uso de hojas de ortigas por los pueblos en la confección de pinturas corporales o en la extracción de pigmentos ${ }^{13}$.

Otro grupo de plantas, pertenecientes al género Renealmia, puede tener una relación con la pintura de las mujeres hi-merimã. Una de estas plantas, la Renealmia aromatica, está presente en los campos abiertos de los jamamadi y suruwaha. La pulpa de sus frutos se utiliza como uno de los ingredientes para una receta de papilla de maíz. Según los jamamadi, la receta de los antiguos no llevaba maíz sino otras masas, probablemente féculas de tuberosas y semillas. Estos pueblos no hacen un cultivo directo de esas plantas. Una vez recolectados los frutos en los campos abiertos cercanos, las semillas se desechan en sitios próximos a las casas y campamentos. En el caso de los suruwaha, por ejemplo, la concentración del kaxiniari, como se conoce entre ellos, señala el lugar de antiguas malocas, y no de viejas rozas abandonadas. En ese contexto etnográfico, las concentraciones de patabás, bacabas y kaxiniari constituyen las taperas (chozas),

13 Entre los arawá, era común el uso de la puca panga (Arrabidaea chica) para la confección de pinturas. El té de puca panga, preparado con sus hojas verdes, crea un líquido rojo empleado para teñir. Los suruwaha cultivan el idiahy (Bixa orellana) en sus rozas. 
Figura 10. Contraste entre el color rojo de la masa del idiahy (Bixa orellana) elaborada por las mujeres suruwaha y la pintura morada extraída de los frutos de Renealmia

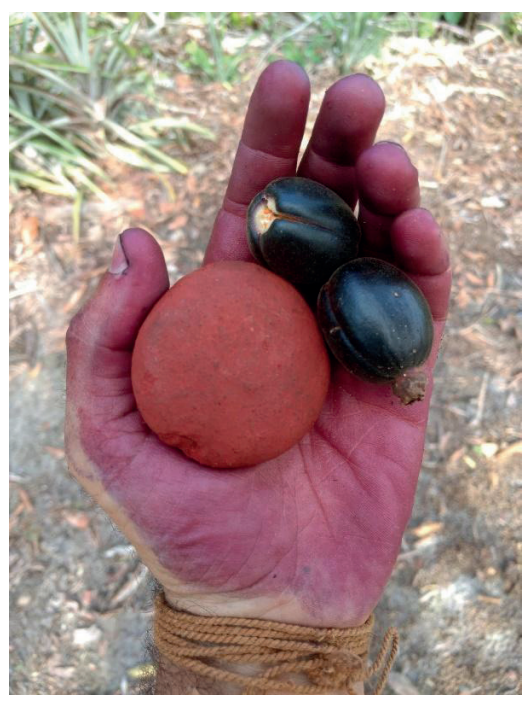

Foto: D. Cangussu/2018.

es decir, las viviendas de los antepasados de estos grupos. Según los jamamadi, los antiguos se pintaban con el zumo de la cáscara del yusi, término por el que designan todas las especies de Renealmia. Las variedades que tienen frutos más pequeños no se utilizan en la alimentación, pero proporcionan igualmente una pintura morada y muy apreciada.

\section{Nota 8. Breas y antorchas en paseos nocturnos}

Las antorchas son uno de los artículos de la cultura material frecuentemente encontrados en el interior de los campamentos de los hi-merimã. Estos vestigios sugieren que los hi-merimã suelen hacer pequeños desplazamientos nocturnos. Tales utensilios en general se confeccionan con las hojas pinnadas de palmeras y ataduras de liana o envira. La punta de la antorcha consiste en una especie de agarradera confeccionada para acoplar un trozo de brea, material combustible que alimenta la llama. A juzgar por el análisis de las antorchas encontradas, las breas más utilizadas son aquellas de las resinas endurecidas de courbaril/azúcar huayo (Hymenaea spp.) y de la mezcla con la de caraño (Protium heptaphyllum). 
Figura 11. Antorcha hi-merimã

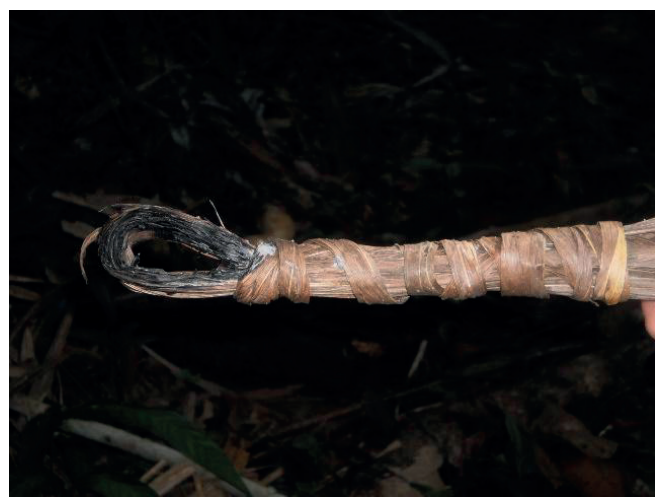

Foto: colección de FPE Madeira-Purus/2012.

En el relato, teniendo en cuenta que la mujer debería caminar por algunas horas hasta alcanzar su campamento, es muy probable que ella haya utilizado su propia antorcha, y no un tizón, como mencionó el señor Domingos.

Nota 9. Vestigios y ruinas en el territorio arawá: la decadencia de las castañas y la hiperdominancia del patabá

En el año 2018 se realizó una expedición de monitoreo en el sector oriental de la Tierra Indígena Hi-Merimã. En esa ocasión, los miembros de la expedición analizaron los vestigios dejados por el grupo aislado en su reciente pasaje por las cabeceras de la quebrada Canuaru, tales como campamentos, senderos, cerámicas, plantas y diversos vestigios de la cultura material con dataciones distintas, lo que revela un uso cíclico del territorio. Uno de los senderos mapeados llevó el equipo hasta un campo abierto en la localidad de São Raimundo, antigua residencia de la familia del señor Domingos según la transcripción del relato.

Así como otros antiguos asentamientos en el territorio de los hi-merimã, esta área tiene castañeras (Bertholletia excelsa) — que no llegan a formar un castañal lo suficientemente grande para la exploración comercial - de copoazú (Theobroma grandiflorum), de cacao (Theobroma cacao), de azaí (Euterpe oleracea), entre otras especies domesticadas exóticas que, aunque están presentes en otras partes de la Amazonía, han sido llevadas a la región por sus antiguos dueños y aún se mantienen, aunque decadentes, a pesar del avance del bosque nativo. Es posible observar las ruinas de las antiguas habitaciones, sobre todo los pilares de cuajada negra (Minquartia guianensis) de las casas de palafitos y parte del barro de la 
Figura 12. Pilares de cuajada negra del antiguo asentamiento de São Raimundo y cerámica hi-merimã

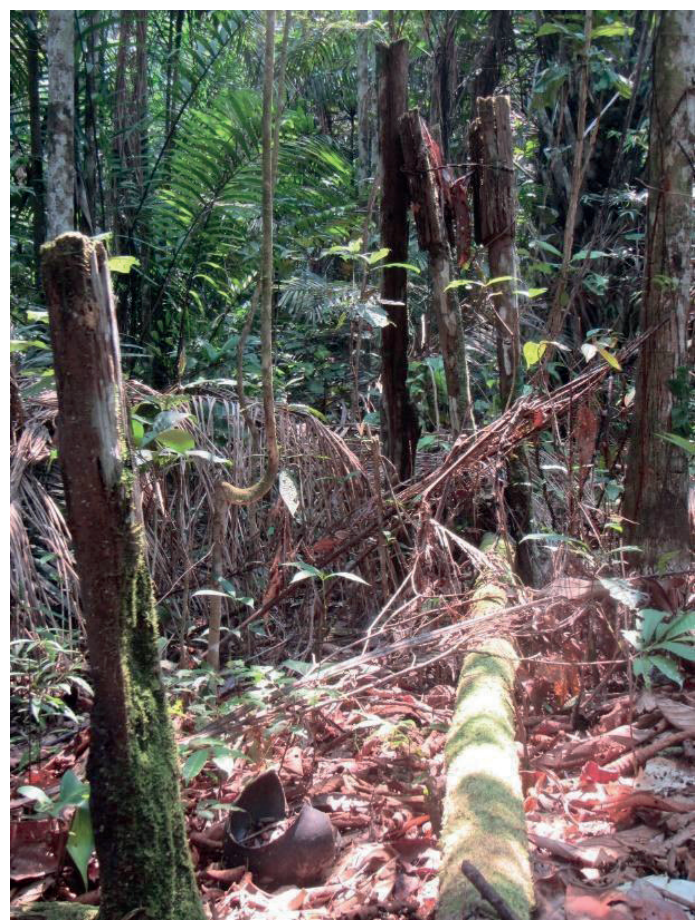

Foto: colección de FPE Madeira-Purus/2018.

estructura del viejo horno de la casa de harina, junto con vasijas esmaltadas y botellas de vidrio. En medio de las ruinas de los blancos están los vestigios y ruinas de los hi-merimã superpuestos en el bosque.

En esa última expedición a los campos abiertos de São Raimundo, los hi-merimã han consumido frutos maduros de azaí y copoazú, y han atado sus hamacas a los viejos pilares de cuajada negra. Había muchos racimos de castaña quemados en el local para facilitar su rompimiento sin comprometer el filo de sus pocos machetes. El hecho que llama la atención en ese contexto es que los hi-merimã tumben los castañeros con el fin de alcanzar los racimos, lo cual causa extrañeza y aflicción en los materos. De hecho, la práctica de la tala de árboles fructíferos es muy común entre los hi-merimã, siendo uno de los vestigios más característicos de este contexto etnográfico. Se observa que las especies de las cuales se consume solo la pulpa y no las semillas — como pasa con la patabá, bacaba y azaí - parecen beneficiarse de esa práctica hi-merimã. 
Aunque las palmeras adultas se talan durante la estadía del grupo en determinada región, ellas forman pequeños nichos enriquecidos debido a la eliminación de las semillas en el interior del bosque. Esa práctica impulsada por la preferencia por las palmeras, acaba protegiendo las semillas de la depredación natural de las grandes manadas de pecaríes y tapires, ya que ellos maceran los frutos y semillas al masticarlos. Por otro lado, los árboles castañeros no parecen beneficiarse de esta práctica de tala, ya que, a diferencia de lo que ocurre con las palmeras, sus semillas se consumen por completo.

Continuando con los castañeros, hay dos características principales que se pueden atribuir a esta especie: una preferencia por áreas abiertas y longevidad. Son plantas heliófitas que se benefician de la presencia de claros, ya sean naturales o abiertos por el hombre. La presencia de castañeros en antiguas áreas habitacionales, como en los sitios arqueológicos de tierra negra, se ha caracterizado como un bioindicador de extensos claros y aldeas en el pasado. En las orillas del río Iriri, afluente del río Xingú, se identificó un castañal bajo un sitio arqueológico que data de, aproximadamente, 2000 A.P. (Balée et al., 2020). Estos aglomerados de árboles pueden tener un largo historial de existencia. En la Amazonía central hay castañales con más de cuatrocientos años de existencia, y constituyen verdaderas «cápsulas del tiempo» para entender el histórico de la relación humana con el bosque (Caetano-Andrade et al., 2019). El castañero es uno de los árboles de uso más antiguo y difundido en la Amazonía. Su presencia ha sido identificada en varios contextos arqueológicos que se remontan al inicio de la ocupación humana, es decir, hace aproximadamente 12000 años (Furquim 2020; Shepard y Ramírez, 2011). Varios grupos indígenas manejan los castañales presentes en sus territorios, aunque su «siembra» en estos contextos está también asociada a los animales que dispersan y entierran las semillas, como los agutíes y las pacas. Los wajãpi, pueblo hablante de una lengua tupí y que vive en el Amapá, dicen que los castañales son las rozas de los agutíes (Oliveira, 2016).

En el caso hi-merimã, sería imprudente afirmar los motivos de la tala de castañeros, ya que esta práctica se extiende a todas las especies. El resultado final de ese manejo son bosques caracterizados por el dominio completo de patabás y una ausencia casi total de castañeros. Los suruwaha incluso no tienen una palabra específica para el castañero y lo asocian a una especie de los jara, es decir, de los blancos. Los castañeros presentes en el territorio hi-merimã, con excepción de pocos árboles aislados en medio del bosque, están por lo tanto asociados a los campos abiertos de los blancos. Todo indica que no son los factores ecológicos/ambientales, sino las singularidades etnográficas arawá las que constituyen 
los determinantes para entender la ausencia de castañales en el interfluvio del curso medio Juruá/Purus. El campo abierto de São Raimundo actualmente se caracteriza por la ascensión de palmeras fructíferas que dividen el espacio con algunos pocos castañeros que aún están en pie, pero no por mucho tiempo.

\section{CONSIDERACIONES FINALES}

Son pocas las informaciones sobre los pueblos aislados en Sudamérica y la bibliografía disponible a menudo se restringe a las políticas públicas de protección territorial. La producción de informaciones y la producción de etnografías sobre los pueblos indígenas continúan siendo un desafío para los investigadores, indigenistas y etnólogos, teniendo en cuenta que el modo «clásico» (no el único) de obtención de datos en estas ciencias se hace a través de la relación directa entre investigadores e investigadoras y sus interlocutores e interlocutoras indígenas. Hay algunas iniciativas que pretenden cambiar ese escenario. Gow (2011), por ejemplo, proporciona una reflexión aguda sobre las limitaciones metodológicas y, en alguna medida, infranqueables. El autor investiga a los mashco, grupo aislado de la Amazonía peruana, a través del relato escrito y de informaciones de los piro (yine). Siguiendo con la discusión metodológica y sus implicaciones políticas, nuestro objetivo en este texto fue ampliar el foco para abarcar las relaciones entre humanos y plantas con el fin de no incurrir en el aislamiento metodológico que ve a los humanos como seres apartados de la multiplicidad simbiótica de sus vínculos.

Partimos del reconocimiento de la relevancia de la ciencia matera para la política indigenista del «no contacto», una vez que ella nos permite reflexionar sobre los pueblos indígenas aislados a través de los vestigios dejados por ellos en los bosques y plantas de sus territorios, pero no se limita a eso. La práctica de campo y la experiencia en los bosques revelan ser igualmente esenciales en la interpretación de la bibliografía disponible, de los registros de viajantes y, sobre todo, en el análisis de testimonios obtenidos entre los pueblos habitantes de los territorios vecinos. A pesar de que el relato presentado no constituye un compendio botánico, las relaciones con las plantas presentadas en él son fundamentales para comprender la dinámica territorial arawá. En ese sentido, la Casimirella ampla es imprescindible y central para pensar la historia agrícola con sus transformaciones en el sur del Amazonas; la tala del castañero señala un cierto anarquismo contradomesticatorio, y los pigmentos vegetales expresan la movilidad de ese grupo aislado no agricultor. 
El concepto de domesticación se somete a una nueva revisión crítica hecha por autores de la llamada etnografía multiespecífica, o por quienes dialogan con ese enfoque para redimensionar la distribución de las agencias en las interacciones entre humanos y no humanos. Para los autores que amplían el sentido de domesticación e insisten en su uso, el concepto asume nuevas formas, como prácticas marcadas por intimidades inesperadas, incertidumbres ontológicas y co-constitución corporal entre los seres. Por tanto, las narrativas sobre la domesticación pueden ser otras, especialmente si son analizadas desde las márgenes, desde un punto de vista descentrado (Swanson et al., 2018).

La ecología histórica emprende una revisión semejante al disociar la domesticación de plantas de la dependencia de formas agrícolas intensivas de cultivo, establecidas con la llamada «revolución neolítica» neotropical (Clement et al., 2021), ampliando, de este modo, el entendimiento del concepto para cualquier forma de alteración vegetal resultante de la relación entre humanos y plantas, sin priorizar la existencia de un punto final estático. La domesticación, en este sentido actualizado, es un proceso continuo de transformaciones.

En el contexto que nos interesa aquí, nos orientamos por la crítica planteada por Carneiro da Cunha (2019), quien establece como punto de partida la relación problemática entre agricultura y propiedad en la filosofía política con el fin de mostrar otro tipo de escenario relacional en la Amazonía, en donde la agricultura no se hace a expensas del bosque, sino que se configura como ciencia del y en el bosque. Por lo tanto, la relación entre los pueblos indígenas y sus cultivos no está basada en el control y en la subordinación, una vez que las plantas tienen sus propias voliciones y, si son descuidadas, se van. De esta forma, los pueblos indígenas se resisten a domesticar y a ser domesticados; además, estos pueblos no toman los intereses humanos como «principio organizador primario» (Ghassan Hage apud Carneiro da Cunha, 2019, p. 132). Esto hace que la domesticación pierda su poder analítico como concepto adecuado para describir lo que pasa en la Amazonía, e incluso en otros lugares, como lo formula Marilyn Strathern (apud Carneiro da Cunha, 2019, p. 129):

In the eyes of many Papua New Guineans, however, planting does not axiomatically ensure that the plant stays there; once in the care of particular gardeners, who may or may not pay them sufficient attention, the souls of both taro and yam may have reason to wander away. If they have come from somewhere else they can go off too, in a kind of reverse movement (Strathern 2017 , p. 33, $\left.\mathrm{N}^{\circ} 11\right)$. 
Cuando se mira conjuntamente el relato y la diversidad de informaciones sobre los pueblos arawá y las plantas que manejan, se nota claramente que los bosques hi-merimã expresan su territorialidad contradomesticatoria (Carneiro da Cunha, 2019). Como ya dijimos aquí, las talas estimulan el crecimiento de las palmeras y acaban promoviendo la protección de las semillas y la renovación de los árboles a lo largo del tiempo; la movilidad, por lo tanto, está en sincronía con la temporalidad vegetal. Paisajes de invierno y paisajes de verano: las pescas con venenos y la búsqueda por frutos maduros generan nichos culturales y senderos a través de los cuales se vislumbra la estacionalidad de sus movimientos en bosques indigeneizados (Cangussu, 2021).

De la misma forma en que estos «aislados» están muy presentes en las aldeas de los grupos vecinos, ellos también conocen y reflexionan sobre el mundo con el que decidieron no relacionarse. Después de todo, basta reiterar, «ningún pueblo es una isla» (Viveiros de Castro, 2019): los hi-merimã guardan y utilizan hachas, vestigios de los tiempos de contacto, y saben nombrar peces en la lengua de los no indígenas, además de monitorear su entorno. De cualquier modo, la forma de la relación de los hi-merimã permanece siendo un rechazo inscrito en los bosques y plantas.

\section{REFERENCIAS BIBLIOGRÁFICAS}

Albuquerque, U. (2005). Introdução à Etnobotânica [segunda edición]. Río de Janeiro: Interciência.

Aparício, M. (2019). A relação banawá: socialidade e transformação no Arawá do Purus [tese de Doutorado]. Museu Nacional. Universidade Federal do Rio de Janeiro.

Balée, W. (2008). Sobre a indigeneidade das paisagens. Revista de Arqueologia, 21(2), 9-23. https://doi.org/10.24885/sab.v21i2.248

Brewer-Carías, C. (2013). Desnudo en la selva: supervivencia y subsistencia. Caracas, Venezuela: Altolitho.

Cangussu, D. (2021). Manual Indigenista Mateiro [dissertação de Mestrado]. Programa de Pós-graduação em Gestão de Áreas Protegidas da Amazônia. INPA.

Cangussu, D. et al. (en prensa). Arqueologia e política do não-contato: sobre o monitoramento e proteção dos territórios de povos indígenas isolados na Amazônia sob a ótica da Ecologia Histórica. 
Cangussu, D. et al. (en prensa). Árvores Atraentes: a sedução vegetal e os povos indígenas em isolamento na Amazônia brasileira.

Carneiro da Cunha, M. (2019). Antidomestication in the Amazon Swidden and its foes. HAU: Journal of Ethnographic Theory, 9(1), 126-136. https://doi. org/10.1086/703870

Clement, C. R. (1999). 1492 and the loss of Amazonian crop genetic resources. The relation between domestication and human population decline. Economy Botany, 53(2), 188-202.

Clement, C. R., De Cristo-Araújo, M., Coppens D’Eeckenbrugge, G., Alves Pereira, A. y Picanço-Rodrigues, D. (2010). Origin and domestication of native Amazonian crops. Diversity, 2(1), 72-106. https://doi.org/10.3390/d2010072

Clement, C. R., Casas, A., Parra-Rondinel, F. A., Levis, C., Peroni, N., Hanazaki, N., ... Mazzochini, G. G. (2021). Desentangling domestication from food production systems in the Neotropics. Quaternary, 4(1). https://doi.org/10.3390/ quat4010004

Doyle, B. J., Svobodny, G. S., Batallas, R., Fernández, D. (2013). Medical Ethnobotany of the Amazonian Kichwa Community of San José de Payamino, Ecuador: An Undergraduate-Level Field Course. ISHS Acta Horticulturae 1030: International Symposium on Medicinal Plants and Natural Products. https://doi.org/10.17660/ ActaHortic.2014.1030.12

Gow, P. (2011). «Me deixe em paz!»: Um relato etnográfico preliminar sobre o isolamento voluntário dos Mashco. Revista de Antropologia - USP, 54(1).

Huber, A. M. (2012). Pessoas falantes, espíritos cantores, almas trovões: história, sociedade, xamanismo e rituais de auto-envenenamento entre os Suruwaha da Amazônia ocidental [tese de Doutorado]. Universidad de Berna.

Instituto Socioambiental - ISA (2019). Um panorama sobre os povos indígenas em isolamento na Amazônia brasileira. En F. Ricardo y M. Góngora (eds.), Cercos e resistências: povos indígenas isolados na Amazônia brasileira. São Paulo: Instituto Socioambiental.

Kinupp, V. F. y Lorenzi, H. (2014). Plantas alimentícias não convencionais (PANC) no Brasil: guia de identificação, aspectos nutricionais e receitas ilustradas. São Paulo: Instituto Plantarum de Estudos da Flora.

Levis, C. (2018). Domestication of Amazonian Forest [tese de Doutorado]. Instituto Nacional de Pesquisa da Amazônia, Manaus.

Mendes dos Santos, G. (2016). Plantas e parentelas - Notas sobre a história da agricultura no Médio Purus. En G. Mendes dos Santos y M. Aparicio (eds.), Redes Arawa - Ensaios de etnologia o Médio Purus (pp. 19-39). Manaus: EDUA. 
Mendes dos Santos, G., Cangussu, D., Furquim, L., Watling, J., Neves, E. (2021). Pão-de-índio e biomassas vegetais: elos entre o passado e o presente na Amazônia indígena. Boletim Ciências Humanas, Revista do Museu Paraense Emílio Goeldi, 16(1). https://doi.org/10.1590/2178-2547-bgoeldi-2020-0012

Moraes, C. P. (2015). O determinismo agrícola na arqueologia amazônica. Revista de Estudos Avançados, 29(83), 25-43. https://doi.org/10.1590/S010340142015000100004

Neves, E. G. (2006). Arqueologia da Amazônia. Río de Janeiro: Jorge Zahar Editora.

Pohl, L. (2000). Relatório de Identificação e Delimitação da Terra Indígena Hi-Merimã. Brasília: Ministério da Justiça. Fundação do Índio.

Politis, G. (2007). Nukak: Crónicas de contacto. En A. Parellada (ed.), Povos indígenas em isolamento voluntário ou em contato inicial na Amazônia e no Gran Chaco (pp. 146- 155). São Paulo: NIME/LABI/USP.

Prance, G. T. (1986). Etnobotânica de algumas tribos Amazônicas. En B. G. Ribeiro (ed.), SUMA Etnológica Brasileira. Edição atualizada do Handbook of South American Indians - Etnobiologia (pp. 119-134). Petrópolis, Río de Janeiro: Vozes.

Raven, P. H., Evert, R. F. y Einchhorn, S. E. (2001). Biologia vegetal [sexta edición]. Río de Janeiro: Guanabara Koogan.

Ribeiro, R. G. (2018). Estudo etnobotânico e físico-químico da batata-mairá (Casimirella spp. Icacinaceae) [dissertação de Mestrado]. Instituto Nacional de Pesquisas na Amazonia, Manaus, Amazonas.

Shepard, G. H. y Ramírez, H. (2011). «Made in Brazil»: Human Dispersal of the Brazil Nut (Bertholletia excelsa, Lecythidaceae) in Ancient Amazonia. Economic Botany, 65, 44-65. https://doi.org/10.1007/s12231-011-9151-6

Shiratori, K. (2018). O olhar envenenado: da metafísica vegetal Jamamadi (médio Purus, AM) [tese de Doutorado]. Museu Nacional, Universidade Federal do Rio de Janeiro.

Shiratori, K., Cangussu, D. y Furquim, L. (2021). Life in tree scenarios: plant controversies between Jammadi gardens and Hi-Merimã palm orchards (Middle Purus River, Amazonas, Brazil). Journal of Anthropological Archeology, 64, 101358. https://doi.org/10.1016/j.jaa.2021.101358

Smith, B. D. (2012). Cultural Niche Construction Theory of Initial Domestication. Biological Theory, 6, 260-271. https://doi.org/10.1007/s13752-012-0028-4

Souza, V. C. y Lorenzi, H. (2012). Botãnica Sistemática: Guia ilustrado para identificação das famílias de Fanérogramas nativas e exóticas no Brasil, baseado em $A P G$ III. São Paulo: Instituto Plantarum. 
Spruce, R. (1951). Journal of a Voyage up the Amazon and Rio Negro. En William Jackson Hooker (ed.), Journal of Botany and Kew Garden Miscellany (pp. 210-212). Londres: John Edward Taylor Pinter.

Stahl, P. W. (2015). Interpreting interfluvial landscape transformations in the pre-Columbian Amazon. The Holocene, 25(10), 1598-1603. https://doi. org/10.1177/0959683615588372

Steege, H., Pitman, N. C., Sabatier, D., Baraloto, C., Salomão, R. P. y Guevara, J. E. (2013). Hyperdominance in the Amazonian tree flora. Science, 342(6156). https://doi.org/10.1126/science.1243092

Swanson, H., Lien, M. y Ween, G. (eds.) (2018). Domestication Gone Wild: Politics and Practices of Multispecies Relations. Nueva York: Duke University Press. https:// doi.org/10.1515/9780822371649

Virtanen, P. K. (2016). Redes terrestres na região do rio Purus que conectam e desconectam os povos Aruak. En G. Mendes dos Santos y M. Aparicio (eds.), Redes Arawa - Ensaios de etnolodia do Medio Purus (pp. 41-61). Manaus: EDUA. 